\title{
COVID-19 Y MEDIDAS SOCIOLABORALES DE EMERGENCIA \\ (RDLEY 6/20, 7/20, 8/20, 9/20, 10/20, 11/20, 12/20 Y 13/20)
}

\author{
Ignasi Beltran de Heredia Ruiz \\ Profesor Agregado y TU Acreditado \\ Universitat Oberta de Catalunya
}

\begin{abstract}
El objeto de este ensayo es proponer una sistematización de las medidas sociolaborales aprobadas por los Reales Decreto-Ley 6/20, 7/20, 8/20, 9/20, 10/20, 11/20, 12/20 y 13/20, para dar respuesta a la alarma santaria provocada por el COVID-19, distinguiendo los siguientes apartados: medidas relativas al contenido y la "ejecución" de la prestación de trabajo; las medidas de naturaleza "prestacional" y de seguridad social; y medidas de naturaleza procesal.

The purpose of this essay is to propose a systematization of socio-labor measures approved by Decree Law 6/20, 7/20, 8/20, 9/20, 10/20, 11/20, 12/20 and 13/20, to face the sanitary alarm caused by COVID-19, distinguishing the following sections: measures relating to the content and "implementation" of the work; "subsidies" and social security measures; and procedural measures.
\end{abstract}

Title. COVID and emergency social labor measures

Palabras clave: COVID-19, estado de alarma, medidas sociolaborales.

Key words: COVID-19, alarm state, socio-labor measures

IUSLabor 1/2020, ISSN 1699-2938, p. 45-110

DOI. 10.31009/IUSLabor.2020.101.03

Fecha envío: 9.4.2020 | Fecha aceptación: 10.4.2020 


\section{Sumario}

1. COVID-19: lo poco conocido y lo improbable

2. Medidas relativas al contenido y ejecución de la prestación de Trabajo

2.1. Medidas de flexibilidad interna a disposición de los trabajadores

2.1.1. Carácter preferente del trabajo a distancia

2.1.2. Derecho a la adaptación de la jornada

2.1.3. Derecho a reducción de jornada (y reducción de salario)

2.1.4. Derecho a novación de la adaptación de jornada o reducción ya existente

2.2. Medidas de flexibilidad interna a disposición del empresario

2.2.1. Medidas de flexibilización de los mecanismos de ajuste temporal de actividad para evitar despidos

2.2.2. Facultades empresariales extraordinarias en el ámbito de los servicios sociales, sanitario y científico

2.3. Medidas de contención del empleo

2.3.1. Protección del empleo, interrupción de la duración y prórroga de contratos temporales

2.3.2. El compromiso de salvaguarda del empleo

2.3.3. Bonificación para el mantenimiento de la actividad de fijos discontinuos

2.4. Medidas de fomento del empleo: la flexibilización laboral en el empleo agrario

2.5. El permiso retribuido recuperable

2.5.1. Delimitación conceptual de los permisos (y de la suspensión y la excedencia)

2.5.2. El permiso retribuido recuperable (PRR)

2.6. Protección y asistencia a víctimas de violencia de género y prevención de riesgos laborales

2.7. Colaboración de empleadas y empleados públicos

3. Medidas "prestacionales" y de apoyo a empleados, autónomos y empreses

3.1. Medidas dirigidas a empleades

3.1.1. Desempleo en caso de suspensión o reducción de jornada por fuerza mayor o CETOP

3.1.2. Subsidio de desempleo excepcional por fin de contrato temporal

3.1.3. Subsidio extraordinario por falta de actividad para las personas integradas en el Sistema Especial de Empleados de Hogar

3.1.4. Compatibilidad del subsidio por cuidado de menor y prestación por desempleo o cese de actividad durante la permanencia del estado de alarm

3.1.5. Incapaciad temporal en situación excepcional de confinamiento total

3.1.6. Efectos de la compatibilidad de la pensión de jubilación con el nombramiento como personal estatutario 
3.1.7. Licencias y abono de retribuciones a los mutualistas de MUFACE y MUGEJU en situación de IT durante la vigencia del estado de alarma

3.2. Medidas de apoyo a las empresas y autónomos

3.2.1. Prestación extraordinaria por cese de actividad de autónomos y socios cooperativistas encuadrados como trabajadores por cuenta pròpia

3.2.2. Moratoria de las cotizaciones sociales a la Seguridad Social

3.2.3. Aplazamiento en el pago de deudas con la Seguridad Social

3.2.4. ERTE por fuerza mayor y exoneración de la cuota empresarial

3.3. Medidas dirigidas a trabajadores por cuenta ajena y autónomos: disponibilidad de los planes de pensiones

4. Ampliación plazo para recurrir y agilización processal

5. Valoración final

6. Bibliografía citada 


\section{COVID-19: lo poco conocido y lo improbable}

Hemos confundido lo poco conocido con lo improbable.

Aunque retrospectivamente la cadena causal de los acontecimientos se desvela absolutamente clara y percibimos (probablemente de forma ilusoria) que lo sucedido era predecible, creo que debemos admitir que hemos desestimado el impacto sistémico del COVID-19 a pesar de las advertencias.

La declaración del Estado de Alarma (RD 463/2020) y los Reales Decreto-Ley 6/2020, 7/2020, 8/2020, 9/2020, 10/2020, 11/2020, 12/2020 y 13/20201 son, al cierre de este artículo, las principales respuestas "paliativas" para tratar de contener los efectos profundamentente desbordantes y exponenciales derivados de la alarma sanitaria.

En un marco de incertidumbre extrema y ante el riesgo de cangrena de ciertos sectores de la economía, la previsión probabilística de los resultados de unos acontecimientos tan desestabilizantes es, simplemente, imposible.

Por consiguiente (y al margen de lo acertado o no de las medidas adoptadas - que, probablemente, sólo podremos evaluar en unos meses), la planificación con carácter anticipado de respuestas legislativas oportunas y eficaces no es concebible. De ahí que, desde un punto de vista político, me temo que, ante una realidad sanitaria que no evoluciona linealmente, no queda más remedio que ir actuando sobre la marcha.

En todo caso, como ha expuesto CAlvo Gallego $(2020,1)$, de forma abrupta, hemos pasado de un contexto jurídico-laboral que daba respuesta a los intereses en juego de

1 En concreto, RD 463/2020, de 14 de marzo, por el que se declara el estado de alarma para la gestión de la situación de crisis sanitaria ocasionada por el COVID-19; RDLey 8/2020, de 17 de marzo, de medidas urgentes extraordinarias para hacer frente al impacto económico y social del COVID-19; RDLey 9/2020, de 29 de marzo, por el que se regula un permiso retribuido recuperable para las personas trabajadoras por cuenta ajena que no presten servicios esenciales, con el fin de reducir la movilidad de la población en el contexto de la lucha contra el COVID-19; RDLey 10/2020, de 29 de marzo, por el que se regula un permiso retribuido recuperable para las personas trabajadoras por cuenta ajena que no presten servicios esenciales, con el fin de reducir la movilidad de la población en el contexto de la lucha contra el COVID19; RDLey 11/2020, de 31 de marzo, por el que se adoptan medidas urgentes complementarias en el ámbito social y económico para hacer frente al COVID-19; RDLey 12/2020, de 31 de marzo, de medidas urgentes en materia de protección y asistencia a las víctimas de violencia de género; y RDLey 13/2020, de 7 de abril, por el que se adoptan determinadas medidas urgentes en materia de empleo agrario.

NOTA: Con posterioridad al envío de este trabajo se ha publicado el RDLey 15/2020, de 21 de abril, de medidas urgentes complementarias para apoyar la economía y el empleo. Puede accederse a una "refundición" de su contenido siguiendo un criterio cronológico (no por materias) en este enlace. 
empresarios y trabajadores, a otro en el que los mismos han quedado supeditados a un interés "superior", como es la salud pública. Convirtiéndose en el elemento central de interpretación e, incluso, forzando la "desnaturalización" de muchas de las instituciones jurídicas2.

El objeto de este ensayo es proponer una sistematización de la avalancha de medidas sociolaborales aprobadas por los citados Reales Decreto-Ley, distinguiendo los siguientes apartados: medidas relativas al contenido y la "ejecución" de la prestación de trabajo (2); las medidas de naturaleza "prestacional" y de seguridad social (3); y medidas de naturaleza procesal (4).

Ante las dificultades de vislumbrar las implicaciones (probablemente profundas y, quizás, sistémicas) de muchas de estas medidas y dada la urgencia de este comentario, el hilo conductor de la exposición en muchos epígrafes será meramente descriptivo de la normativa (y con una aproximación en la que prima lo esquemático).

En un contexto de volatibilidad legislativa extrema (y en el que la vigencia de alguna de estas medidas puede que sea efímera3), la prudencia en las valoraciones críticas debería primar. No obstante, a pesar del riesgo de incurrir en valoraciones precipitadas (o directamente erróneas), permítanme que, hasta donde mi conocimiento alcanza, en algunos epígrafes trate de complementar la exposición con algunas anotaciones críticas.

\section{Medidas relativas al contenido y ejecución de la prestación de trabajo}

En relación al contenido y la ejecución de la prestación de trabajo se han adoptado medidas de flexibilidad interna (a disposición de trabajadores y empresarios) y de contención del empleo (2.1 a 2.3); medidas de fomento del empleo (2.4); el

\footnotetext{
2 En todo caso, como apunta FERNÁNDEZ AVILES (2020: 19), no debe olvidarse que "las medidas no van a alcanzar a ciertos sectores de la población más desprotegidos".

3 Según la DF 4 4 , las medidas previstas en el RDLey 7/20 mantendrán su vigencia mientras el Gobierno determine que "persisten las circunstancias extraordinarias que motivaron su aprobación". Por su parte, la DF $3^{a}$ establece que las medidas previstas en el RDLey 9/20 mantendrán su vigencia durante el estado de alarma decretado por el RD 463/20 y sus posibles prórrogas. Y, según la DF $10^{\mathrm{a}}$ (modificada por la DF 1.17 RDLey 11/20), las medidas previstas en el RDLey 8/20, que pueden prorrogarse por RDLey, con carácter general, mantendrán su vigencia hasta un mes después del fin de la vigencia de la declaración del estado de alarma (salvo las de aquellas que tengan un plazo determinado de duración, que se sujetarán al mismo). En términos similares, también lo declara la DF $12^{\mathrm{a}}$ para las medidas previstas en el RDLey 11/20. Por su parte, según la DF 6 a el RDLey 13/20 estará vigente hasta el 30 de junio de 2020 (salvo el contenido de las DA $3^{\mathrm{a}}$ y del apartado $1^{\mathrm{o}}$ de la DA $4^{\mathrm{a}}$ - hasta que, una vez finalizado el estado de alarma, se normalice el funcionamiento de las respectivas oficinas públicas).
} 
controvertido permiso retribuido recuperable (2.5); medidas de prevención de riesgos laborales específicas en el ámbito de la atención y asistencia a las víctimas de violencia de género (2.6); y, finalmente, medidas de colaboración de empleados públicos de sectores sanitarios y sociales más allá de su administración de origen (2.7).

A continuación, se procederá a su exposición siguiendo esta sistematización brevemente expuesta.

\subsection{Medidas de flexibilidad interna a disposición de los trabajadores}

\subsubsection{Carácter preferente del trabajo a distancia}

El RDLey 8/20 ( artículo 5) prevé la promoción del trabajo a distancia, con carácter prioritario frente a la cesación temporal o reducción de la actividad. Aunque la norma no lo especifique, es probable que la priordad ( $\sin$ ser absoluta e incondicionada) es "imponer el establecimiento, no ya de cualquier tipo de trabajo a distancia -tal cómo es definido en el artículo 13 ET- sino, seguramente, y de forma más específica, del trabajo o del teletrabajo -si hay uso intensivo, como suele haberlo, de las TIC- a domicilio, evitando así las concentraciones y los desplazamientos que pudieran favorecer la rápida difusión del virus"4.

En estas situaciones, para el cumplimiento de la evaluación de riesgos laborales, basta la autoevaluación realizada voluntariamente por la propia persona trabajadora.

En este caso es la empresa la que tiene que adoptar las medidas oportunas si ello es técnica y razonablemente posible y si el esfuerzo de adaptación necesario resulta proporcionado.

Aunque, aparentemente no se está reconociendo un derecho unilateral del trabajador al trabajo a distancia, debe tenerse en cuenta que el artículo 6, sobre adaptación de la jornada (como se analizará) sí lo admite esta posibilidad. No obstante, es razonable pensar que el trabajo a distancia sólo sea factible en aquellas circunstancias que efectivamente pueda prestarse (y si la actividad en cuestión puede desarrollarse en estas condiciones)5.

\subsubsection{Derecho a la adaptación de la jornada}

\section{Calvo Gallego $(2020,2)$,}

5 Una extensa y excelente aproximación a esta medida, así como a sus implicaciones en CALVO GALLEGO $(2020,2)$, 
El artículo 6.1 RDLey 8/20 establece un conjunto de reglas específicas respecto al derecho a la adaptación de jornada (previsto, como saben, en el artículo 34.8 ET). En concreto, se configura como un derecho individual, que debe incardinarse en el reparto corresponsable, para el cuidado del cónyuge o pareja de hecho y familiares por consanguinidad hasta el segundo grado.

En concreto, puede acudirse a esta medida, si:

- Por razones de edad, enfermedad o discapacidad, necesite de cuidado personal y directo como consecuencia directa del COVID-19; o

- Por decisiones adoptadas por las Autoridades gubernativas relacionadas con el COVID-19 que impliquen cierre de centros educativos o de cualquier otra naturaleza que dispensaran cuidado o atención a la persona necesitada de los mismos; o

- Quien se estaba ocupado del cuidado no pudiera seguir haciéndolo por causas justificadas relacionadas con el COVID-19.

a. Condiciones de ejercicio

- Justificación y proporcionalidad: Este derecho debe ser justificado, razonable y proporcionado en relación con la situación de la empresa, particularmente en caso de que sean varias las personas trabajadoras que acceden al mismo en la misma empresa (los conflictos deberán resolverse por el cauce que prevé el artículo 139 LRJS - aunque la suspensión de actividad de los órganos jurisdiccionales podría dificultar extraordinariamente la resolución de estas controversias6).

- Concreción inicial corresponde al trabajador: La concreción inicial de esta prerrogativa corresponde a la persona trabajadora, tanto en su alcance como en su contenido, siempre y cuando esté justificada, sea razonable y proporcional (atendiendo a la necesidad que se pretende cubrir y la situación de la empresa).

- Acuerdo: el RDLey establece que empresa y trabajador «deberán hacer lo posible por llegar a un acuerdo». No especifica qué sucede en caso de desacuerdo. En todo caso, en la medida que, a diferencia del artículo 34.8 ET, se está reconociendo un derecho a la adaptación (y no un derecho a la solicitud de la adaptación), podría entenderse que la posición de los trabajadores tendría una configuración preeminente. 
- El ejercicio de este derecho no comporta una reducción de salario.

b. Contenido de la adaptación (opciones posibles)

Distribución del tiempo de trabajo o a cualquier otro aspecto de las condiciones de trabajo, cuya alteración o ajuste permita que la persona trabajadora pueda dispensar la atención y cuidado objeto del presente artículo.

Puede consistir en cambio de turno, alteración de horario, horario flexible, jornada partida o continuada, cambio de centro de trabajo, cambio de funciones, cambio en la forma de prestación del trabajo, incluyendo la prestación de trabajo a distancia, o en cualquier otro cambio de condiciones que estuviera disponible en la empresa o que pudiera implantarse de modo razonable y proporcionado.

\subsubsection{Derecho a reducción de jornada (y reducción de salario)}

Se reconoce ( artículo 6.3 RDLey 8/20) el derecho a una reducción de la jornada de trabajo en las situaciones previstas en el artículo 37.6 ET en algunas de las 3 situaciones descritas para los supuestos de adaptación de jornada anteriormente descritos, con la reducción proporcional de su salario.

En concreto, las condiciones de ejercicio son las siguientes:

Sujeción a las reglas previstas en los artículos. 37.6 y 37.7 ET con las siguientes particularidades:

- Comunicación a la empresa con 24 horas de antelación.

- Puede alcanzar el 100\% de la jornada (sin que implique cambio en los derecho y garantías establecidos en el artículo 37.6 ET). Esta posibilidad máxima debe estar justificada y ser razonable y proporcionado en atención a la situación de la empresa. En todo caso, personalmente, creo que todas aquellas situaciones próximas a este \% también lo deberían ser.

- En el caso previsto en el artículo 37.6.2 ${ }^{\circ}$ ET no es necesario que el familiar que requiere atención y cuidado no desempeñe actividad retribuida (debe recordarse que este supuesto se refiere a "cuidado directo de un familiar, hasta el segundo grado de consanguinidad o afinidad, que por razones de edad, accidente o enfermedad no pueda valerse por sí mismo"). 
2.1.4. Derecho a novación de la adaptación de jornada o reducción ya existente

En el caso de que la persona trabajadora se encontrara disfrutando ya de una adaptación de su jornada por conciliación, o de reducción de jornada por cuidado de hijos o familiares, o de alguno de los derechos de conciliación previstos en el ordenamiento laboral, incluidos los establecidos en el propio artículo 37, el artículo 6.4 RDLey 8/20 le faculta para renunciar temporalmente a él o tendrá derecho a que se modifiquen los términos de su disfrute.

Esta facultad está condicionada a la concurrencia de las 3 circunstancias excepcionales descritas anterioremente con respecto a la adpación de jornada. Por otra parte, debe tenerse en cuenta que el mismo precepto establece que la solicitud debe limitarse al periodo excepcional de duración de la crisis sanitaria y acomodarse a las necesidades concretas de cuidado que debe dispensar la persona trabajadora, debidamente acreditadas, así como a las necesidades de organización de la empresa, presumiéndose que la solicitud está justificada, es razonable y proporcionada salvo prueba en contrario.

\subsection{Medidas de flexibilidad interna a disposición del empresario}

2.2.1. Medidas de flexibilización de los mecanismos de ajuste temporal de actividad para evitar despidos

El RDLey 8/20 prevé un conjunto de reglas dirigidas a adaptar el régimen jurídico de la suspensión y reducción del contrato de trabajo por fuerza mayor y causas económicas técnicas organizativas y de producción, pero sin modificar el régimen jurídico vigente7. Esta simultaneidad en el tiempo del régimen jurídico "ordinario" con el derivado de la alarma sanitaria puede plantear conflictos a la hora de concretar el ámbito de aplicación de cada uno (de hecho, esto permitiría que pueda acudirse al ordinario finalizada la alarma).

En todo caso, es importante tener en cuenta que aunque el RDLey 8/20 habilita el recurso al ERTE de forma generalizada, el artículo 1 RDLey 9/20 establece que (con independencia de su titularidad pública o privada o el régimen de gestión) los centros sanitarios y centros sociales de mayores, personas dependientes o personas con discapacidad, en los términos especificados por los departamentos ministeriales competentes, en tanto que prestan servicios esenciales (conforme a lo previsto en el RD 463/20), deben "mantener su actividad, pudiendo únicamente proceder a reducir o

7 En este sentido también, CALVo Y RodRíGUEZ-PIÑERO (2020), 
suspender la misma parcialmente en los términos en que así lo permitan las autoridades competentes".

$\mathrm{Y}$ añade que el incumplimiento o la resistencia a las órdenes de las autoridades competentes en aras al cumplimiento de lo previsto en este artículo será sancionado con arreglo a las leyes ex artículo diez de la LO 4/1981.

Por otra parte, la DA $1^{\text {a }}$ RDLey 9/20 puntualiza que la duración de los ERTE por fuerza mayor ex artículo 22 RDLey 8/20 que hayan sido aprobados por silencio administrativo («con independencia del contenido de la solicitud empresarial concreta») queda circunscrita a la del estado de alarma (al igual que en los que haya recaído resolución expresa).

En la medida que esta disposición confirma el silencio positivo de los ERTE de esta naturaleza8, ante la avalancha de solicitudes y la imposibilidad material de dar respuesta por parte de la Autoridad Laboral, como se expondrá posteriormente, la DA $2^{\mathrm{a}}$ el RDLey 9/20 también «recuerda» que cabe imponer las «sanciones correspondientes» previstas en la LISOS si, mediante solicitudes que contienen falsedades 0 incorrecciones, se ha procedido a la indebida percepción de prestaciones de desempleo; y, además, las extiende a los supuestos en los que las medidas solicitadas no resultaran necesarias o no tuvieran conexión suficiente con la causa que las origina siempre que den lugar a la generación o percepción de prestaciones indebidas.

Finalmente, es importante tener en cuenta que las mismas van dirigidas exclusivamente al sector privado, pues, el RDLey 8/20 no establece ninguna disposición que afecte al contenido de la DA $17^{\mathrm{a}}$ del ET, cuya vigencia se mantiene íntegra9.

a. Particularidades respecto al procedimiento previsto en el artículo 47 ET (suspensión de contratos y reducción de jornada) por causa de fuerza mayor

Las medidas excepcionales en relación con los procedimientos de suspensión de contratos y reducción de jornada por causa de fuerza mayor previstas en el artículo 22 RDLey 8/20 parten de la siguiente "definición" de la fuerza mayor (apartado 1):

"Las suspensiones de contrato y reducciones de jornada que tengan su causa directa en pérdidas de actividad como consecuencia del COVID-19, incluida la

8 Sobre el silencio positivo en este contexto véase MERCADER UGUINA $(2020,1)$

9 Recuérdese: “Lo previsto en el artículo 47 no será de aplicación a las Administraciones Públicas y a las entidades de derecho público vinculadas o dependientes de una o varias de ellas y de otros organismos públicos, salvo a aquellas que se financien mayoritariamente con ingresos obtenidos como contrapartida de operaciones realizadas en el mercado". 
declaración del estado de alarma, que impliquen suspensión o cancelación de actividades, cierre temporal de locales de afluencia pública, restricciones en el transporte público $y$, en general, de la movilidad de las personas y/o las mercancías, falta de suministros que impidan gravemente continuar con el desarrollo ordinario de la actividad, o bien en situaciones urgentes $y$ extraordinarias debidas al contagio de la plantilla o la adopción de medidas de aislamiento preventivo decretados por la autoridad sanitaria que queden debidamente acreditados"10.

Las especificidades respecto del procedimiento son las siguientes ( artículo 22.2 RDLey 8/20)11:

- Inicio del procedimiento: La solicitud de la empresa, acompañando un informe relativo a la vinculación de la pérdida de actividad como consecuencia del COVID19, así como, en su caso, de la correspondiente documentación acreditativa.

- Comunicación a los trabajadores y a la RLT: Debe comunicarse a los trabajadores y traslado del informe y documentación a la RLT.

- Constatación de la fuerza mayor por parte de la Autoridad laboral: Este trámite es exigible "cualquiera que sea el número de personas trabajadoras afectadas" 12.

- Resolución de la autoridad laboral: En un plazo de 5 días desde la solicitud, previo informe (potestativo para la autoridad laboral), de la ITSS (que debe evacuarse en el plazo improrrogable de cinco días).

- Contenido de la resolución: La resolución debe limitarse a constatar la existencia, cuando proceda, de la fuerza mayor alegada por la empresa.

- Adopción de la medida: Constatada la existencia de fuerza mayor, corresponde a la empresa decidir sobre la aplicación de medidas de suspensión de los contratos o

10 Sobre esta conceptuación puede consultarse la «Nota sobre expedientes suspensivos y de reducción de jornada por COVID-19», de 28 de marzo 2020 (DGE-SGON-841CRA), de la Dirección General de Trabajo, especificando cuándo debe entenderse que se está ante una fuerza mayor. Y, extensamente sobre la conceptualización de estas causas en BELTRAN DE HEREDIA RUIZ (2020, 1).

11 Véase también la exposición crítica de este régimen jurídico de CALVO y RoDRÍGUEZ-PIÑERO (2020).

12 Extensamente sobre la «constatación» por parte de la autoridad laboral véase, BELTRAN DE HEREDIA $(2020,2)$. Y una síntesis de algunos casos de fuerza mayor tratados por los Tribunales en, BELTRAN DE HEREDIA $(2020,3)$. En relación a la acreditación de estas situaciones según el RDLey 8/2020, véase Beltran DE HEREDIA (2020, 1). 
reducción de jornada, que surtirán efectos desde la fecha del hecho causante de la fuerza mayor.

- Socios trabajadores de cooperativas de trabajo asociado y sociedades laborales: Debe seguirse el procedimiento previsto en el RD 42/1996 (salvo en el plazo para la resolución de la autoridad laboral y el informe de la inspección)13.

Por otra parte, en los expedientes de suspensión de contratos y reducción de jornada autorizados en base a fuerza mayor ex artículo 22 RDLey 8/20, también se prevén algunas medidas de exoneratorias de las cuotas empresariales ( artículo 24 RDLey 8/20)14.

b. Particularidades respecto al procedimiento previsto en el artículo 47 ET (suspensión de contratos y reducción de jornada) por causa económica, técnica, organizativa y de producción

Las particularidades respecto del régimen vigente previstas en el artículo 23 RDLey 8/20 afectan básicamente al período de consultas y el informe de la ITSS.

En concreto, son las siguientes:

Período de consultas: En caso de no existir RLT, la comisión representativa para la negociación del periodo de consultas (y que debe estar constituida en un plazo improrrogable de 5 días) estará integrada por los sindicatos más representativos y representativos del sector al que pertenezca la empresa y con legitimación para formar parte de la comisión negociadora del convenio colectivo de aplicación. La comisión estará conformada por una persona por cada uno de los sindicatos que cumplan dichos requisitos, tomándose las decisiones por las mayorías representativas correspondientes. En caso de no conformarse esta representación, la comisión estará integrada por tres trabajadores de la propia empresa, elegidos según lo previsto en el artículo 41.4 ET15.

El periodo de consultas no debe exceder del plazo máximo de siete días.

13 En el caso de los ERTE por fuerza mayor o CETOP ex arts. 22 y 23 RDLey 8/2020 adoptados en las sociedades cooperativas, el art. 4 RDLey 9/20 habilita al Consejo Rector a asumir la competencia para adoptar dichas medidas en el caso de que «por falta de medios adecuados o suficientes la Asamblea General de las sociedades cooperativas no pueda ser convocada para su celebración a través de medios virtuales». En relación al impacto del COVID en régimen profesional de las cooperativas véase, ARRIETA IRIAKEZ (2020).

14 Ver al respecto en el epígrafe en el epígrafe 3.2.4.

15 En relación a la problemática que este período de consultas suscita veáse NIETO ROJAS (2020), especialmente, el hecho de que su número parece ser mínimo (en vez de máximo ex art. 41.4). 
Informe ITSS: El informe de la ITSS, cuya solicitud será potestativa para la autoridad laboral, se evacuará en el plazo improrrogable de siete días.

c. Control de la adecuación de las causas del ERTE y régimen sancionador

La posibilidad de que se den comportamientos faudulentos, como consecuencia de la imposibilidad de la Autoridad Laboral de dar curso en plazo a la avalancha de solicitudes y el silencio positivo, el RDLey 9/20 también prevé dos tipos de actuaciones:

- En primer lugar, la citada DA 2a RDLey 9/20 establece la adopción sanciones ex LISOS para el caso de que las "medidas solicitadas no resultaran necesarias o no tuvieran conexión suficiente con la causa que las origina y siempre que den lugar a la generación o percepción de prestaciones indebidas». El RDLey 9/20 califica estos supuestos como «incumplimientos” y esto:

"dará lugar a la revisión de oficio del acto de reconocimiento de dichas prestaciones. En tales supuestos, y sin perjuicio de la responsabilidad administrativa o penal que legalmente corresponda, la empresa deberá ingresar a la entidad gestora las cantidades percibidas por la persona trabajadora, deduciéndolas de los salarios dejados de percibir que hubieran correspondido, con el límite de la suma de tales salarios".

Téngase en cuenta que estas sanciones pueden imponerse sin necesidad de que se hayan hecho solicitudes que contengan "falsedades o incorrecciones en los datos" (como se prevé en relación a la obtención de prestaciones por desempleo de forma indebida).

Extremo que, por otra parte, confirma que la acreditación de los ERTE ex artículos 22 y 23 RDLey 8/20 exige justificar el efecto imposibilitante de la misma sobre la prestación de trabajo.

Aunque la finalidad disuasiva que persigue esta disposición es comprensible (dada la situación de colapso de la autoridad laboral), personalmente creo que se trata de una sanción que compromete la seguridad jurídica. Especialmente si se tiene en cuenta que la apreciación de la necesidad de las medidas adoptadas o de la conexión suficiente de las mismas con la causa que las origina son cuestiones que pueden ser difíciles de determinar y sobre las que, además, pueden existir criterios de apreciación notablemente dispares. 
Aunque es el momento para apreciar como sociedad cual es nuestro «factor de tolerancia» frente a las actitudes deshonestas 16, creo que el propósito de prevenir los comportamientos oportunistas que esta específica disposición persigue puede derivar en notables controversias jurídicas.

- En segundo lugar, la citada DA 4a RDLey 9/20 también prevé que la ITSS, en colaboración con la AEAT y las Fuerzas y Cuerpos de Seguridad del Estado, incluirá, entre sus planes de actuación, la comprobación de la existencia de las causas alegadas en las solicitudes y comunicaciones de ERTE ex artículos. 22 y 23 RDLey $8 / 20$.

2.2.2. Facultades empresariales extraordinarias en el ámbito de los servicios sociales, sanitario y científico

El artículo 36 RDLey 8/20 faculta a las entidades públicas integrantes del Sistema Español de Ciencia, Tecnología e Innovación, cuando deban desarrollar medidas excepcionales en el ámbito de la gestión de la emergencia sanitaria causada por el coronavirus COVID-19, a establecer jornadas laborales extraordinarias para sus trabajadores y trabajadoras (y que se compensarán económicamente a través del complemento de productividad o gratificaciones extraordinarias) 17 .

En términos similares, la Orden SND/295/2020, de 26 de marzo, por la que se adoptan medidas en materia de recursos humanos en el ámbito de los servicios sociales ante la situación de crisis ocasionada por el COVID-19, faculta para establecer en este ámbito "medidas necesarias para la protección de las personas, bienes y lugares, pudiendo imponer a los trabajadores y trabajadoras de los servicios sociales la prestación de servicios extraordinarios, ya sea en razón de su duración o de su naturaleza".

16 Ver al respecto, BELTRAN DE HEREDIA (2019).

17 Además, el art. 36.2 RDLey 8/20 establece que "De conformidad con lo dispuesto en la Disposición adicional vigesimotercera de la Ley 14/2011, de 1 de junio, de la Ciencia, la Tecnología y la Innovación, se autoriza a las entidades públicas integrantes del Sistema Español de Ciencia, Tecnología e Innovación a realizar contratos indefinidos y temporales de acuerdo con la normativa vigente y con los principios de igualdad, mérito, capacidad, publicidad y concurrencia, para la ejecución de planes y programas públicos de investigación científica y técnica o de innovación relacionados con el coronavirus COVID19, debiendo los contratos indefinidos ser financiados mediante consignaciones presupuestarias anuales consecuencia de ingresos externos de carácter finalista. Dichos contratos deberán ser comunicados a los Ministerios de Hacienda y Política Territorial y Función Pública”. 


\subsection{Medidas de contención del empleo}

2.3.1. Protección del empleo, interrupción de la duración y prórroga de contratos temporales

El artículo 2 RDLey 9/20 establece una medida extraordinaria para la protección del empleo, al limitar la posibilidad de despedir o extinguir el contrato alegando algunas de las causas previstas en los artículos. 22 y 23 RLey 8/20 (esto es, la fuerza mayor y CETOP relacionadas con el COVID-19).

Téngase en cuenta que esta medida es distinta a la prevista en el «compromiso de salvaguarda del empleo» ex DA $6{ }^{\text {a }}$ RDLey $8 / 20$ que, como se apuntará, «condiciona» las medidas extraordinarias que se prevén en el RDLey 8/20 "al compromiso de la empresa de mantener el empleo durante el plazo de seis meses desde la fecha de reanudación de la actividad".

Aunque el artículo 2 citado no prevé un marco temporal, estimo que ambas reglas, $a$ priori, no se solaparían, pues, las causas descritas en los artículos 22 y 23 RLey 8/20 sólo pueden alegarse mientras se mantenga la situación de alarma y, en cambio, la DA $6^{\mathrm{a}}$ se «activa» precisamente cuando finaliza la misma.

A su vez, el contenido del artículo 2 también afectaría a la posibilidad de resolver los contratos que ya estén suspendidos en virtud de un ERTE por fuerza mayor o CETOP derivados del estado de alarma.

Por otra parte, téngase en cuenta que el artículo 2 no especifica qué calificación jurídica debería atribuirse a estas extinciones. Esto es, si nulidad o improcedencia. A mi entender, no cabría declarar la nulidad18. Especialmente porque, ante la falta de especificación normativa al respecto, debe entenderse que el criterio jurisprudencial vigente prevalece. En este sentido, esta doctrina (por todas, STS 5 de mayo 2015, rec. 2659/2014) ha establecido que

"Cuando no hay causa legal para la extinción del contrato de trabajo y la causa real no se encuentra entre las tipificadas como determinantes de la nulidad del despido -concluye STS 29-2- 2001 (citada)- la calificación aplicable es la de improcedencia' del despido, y no la de nulidad del mismo"19.

18 En términos similares, CALvo Gallego $(2020,4)$.

19 Defendiendo la nulidad, BAYLOS GRAU (2020). Rojo TORRECILlA (2020), por su parte, afirma “quizás hubiera sido necesario un esfuerzo del legislador por manifestarlo de forma expresa y no tener que llevar 
Por otra parte, debe evaluarse el impacto del artículo 2 RDLey 9/20 en los contratos temporales extinguidos por el cumplimiento del término. En estos casos, siempre que la causa de temporalidad sea lícita, es claro que la ineficacia contractual sería ajena al estado de alarma y, por consiguiente, su extinción se produciría lícitamente al amparo del artículo 49.1.c ET. Y, probablemente, lo mismo también sería extensible a los supuestos de desistimiento durante el período de prueba. En este sentido (aunque se trata de una cuestión de compleja acreditación), no descarto que, según las circunstancias en las que se produzca, se entienda que el empresario ha hecho un uso abusivo del mismo y, por consiguiente, pueda calificarse como ilícito.

En relación a los contratos temporales, también debe evaluarse si el artículo 5 RDLey 9/20 tendría alguna afectación al respecto. En virtud de esta disposición, para el caso de que se proceda a un ERTE por fuerza mayor o CETOP derivados del estado de alarma, se interrumpe del cómputo de su duración de los contratos temporales (incluidos los formativos, de relevo e interinidad) y de los periodos de referencia equivalentes.

Se trata de una medida importante de protección del empleo, aunque puede plantear algunos «desajustes» en aquellas situaciones en las que el objeto del contrato ya no pueda cumplirse. Especialmente, porque una vez superada la alarma sanitaria y restablecida la normalidad, puede suponer que las personas trabajadoras no tengan cometido alguno que hacer. Y el hecho de que la empresa está sujeta al compromiso de salvaguarda del empleo (la citada DA 6 ${ }^{\text {a }}$ ) podría delimitar un escenario de gestión compleja.

En todo caso, a mi modo de ver, el contenido del artículo 5 no afecta a la regla prevista en el artículo 2 RDLey 9/20. De modo que, en el caso de que una empresa no haya procedido a un ERTE $e x$ artículos. 22 y 23 RDLey 8/20, podría acudir a la extinción de los contratos temporales por cumplimiento del términos de forma ordinariaz.

Por otra parte, reparen que el artículo 5 se refiere a la «suspensión» (emplea este término en dos ocasiones), de modo que si el ERTE implicara una reducción de jornada (aunque fuera «vertical») no se cumplirían los requisitos del precepto para interrumpir

la defensa de la tesis a la vulneración del derecho constitucional al trabajo (art. 35, no es derecho fundamental) en su relación muy directa ahora con el de protección de la integridad física y salud (art. $15 \mathrm{CE}$, sí fundamental pero no pensado en clave de relaciones de trabajo). Es probable entonces que la vía de la declaración de improcedencia prevaleciera, pero en tal caso, permítanme y discúlpenme que esté dando vueltas a la cuestión como un tiovivo, ¿no se habría vaciado de contenido real y útil la norma que pretende justamente que no se den tales despidos o extinciones? Como ven tengo más de una y dos dudas, que iré contrastando con mis compañeros y compañeras del mundo laboralista para intentar aclarar algo más, como mínimo, mis ideas".

20 En términos similares, CALvo Gallego $(2020,5)$. 
la duración del contrato temporal. De modo que, en estos casos, en la medida que el artículo 5 no sería aplicable, podrían extinguirse los contratos de forma ordinaria.

En el sector público, no obstante, la situación puede ser especialmente compleja, pues, como se ha apuntado, el RDLey $8 / 20$ no ha afectado a la DA $17^{\text {a }}$ del ET, de modo que no cabe acudir a un ERTE. Por consiguiente, no se estaría dando la condición para poder interrumpir la duración de los contratos e impedir la extinción por cumplimiento ordinario del término. Y esto podría tener una profunda afectación en el ámbito local y el empleo vinculado a programas subvencionados (que hayan quedado afectados por el Estado de alarma) y que atiende a servicios de naturaleza esencial.

Por otra parte, el RDLey 11/20 también contiene reglas específicas en relación a la prórroga de ciertos colectivos de trabajadores. En concreto, la DA $12^{\mathrm{a}}$ prevé la prórroga de los contratos de ayudantes, profesores ayudantes doctores, profesores asociados y profesores visitantes, celebrados conforme a los artículo 49, 50, 53 y 54 LO 6/2001, cuya duración máxima esté prevista que finalice durante la vigencia del estado de alarma y de sus prórrogas, según las reglas siguientes, salvo pacto en contrario:

- Prórroga por una extensión equivalente al tiempo de duración del estado de alarma y, en su caso, sus prórrogas.

- Excepcionalmente, por motivos justificados, las partes podrán acordar, con carácter previo a la fecha de finalización del contrato, una prórroga del mismo por hasta tres meses adicionales al tiempo de duración del estado de alarma y sus prórrogas.

La duración de los contratos prorrogados en aplicación de esta DA podrá exceder los límites máximos previstos para los mismos en la LO 6/2001.

Y, por otra parte, en relación a la duración contratos temporales de investigadores y del personal integrado en el Sistema Nacional de Salud, la DA 13a RDLey 11/20 prevé la posibilidad de prorrogar (siempre que medie acuerdo) durante el tiempo de duración del estado de alarma de los contratos de duración determinada con cargo a la financiación procedente de convocatorias de ayudas de recursos humanos realizadas en el marco de la Ley 14/2011, exclusivamente cuando reste un año o menos para la finalización de los mismos.

Por motivos justificados se podrán prorrogar los contratos por hasta tres meses adicionales al tiempo de duración del estado de alarma y sus prórrogas.

En el caso de que los contratos han sido suspendidos para posibilitar que las personas contratadas se integren en el Sistema Nacional de Salud para atender las contingencias 
derivadas de la situación de emergencia sanitaria debe adicionarse el tiempo de suspensión.

En todo caso, de forma similar a lo previsto en el ámbito universitario, la duración total del contrato de trabajo y de su eventual prórroga podrá exceder los límites temporales máximos previstos en la Ley 14/2011.

\subsubsection{El compromiso de salvaguarda del empleo}

La DA 6 a RDLey 8/20, como se ha avanzado, prevé que "las medidas extraordinarias en el ámbito laboral previstas en el presente real decreto ley estarán sujetas al compromiso de la empresa de mantener el empleo durante el plazo de seis meses desde la fecha de reanudación de la actividad". Se trata de una disposición ciertamente críptica, pues, la "sujeción a un compromiso", sin indicar cuál, ni tampoco las consecuencias derivadas de su incumplimiento delimita un ámbito de indefinición particularmente complejo (especialmente, porque su interpretación puede derivar múltiples y heterogéneas interpretaciones) 21.

De hecho, esta disposición ha sido matizada por la DA $14^{\text {a }}$ del RDLey $11 / 20$ al establecer que este compromiso

"se valorará en atención a las características específicas de los distintos sectores y la normativa laboral aplicable, teniendo en cuenta, en particular, las especificidades de aquellas empresas que presentan una alta variabilidad o estacionalidad del empleo o una relación directa con eventos o espectáculos concretos, como sucede, entre otros, en el ámbito de las artes escénicas, musicales, cinematográfico y audiovisual. En particular, en el caso de contratos temporales el compromiso de mantenimiento del empleo no se entenderá incumplido cuando el contrato se extinga por expiración del tiempo convenido o la realización de la obra o servicio que constituye su objeto o cuando no pueda realizarse de forma inmediata la actividad objeto de contratación.

En todo caso, las medidas previstas en los artículos 22 a 28 de Real Decreto-ley 8/2020, de 17 de marzo, resultarán de aplicación a todas las personas trabajadoras, con independencia de la duración determinada o indefinida de sus contratos".

21 Ver al respecto, Mercader Uguina $(2020,2)$, quien entiende que "el alcance del compromiso de empleo quedaría circunscrito, exclusivamente, a los ERTEs derivados de fuerza mayor en los que se solicitase la exención de cuotas y, por tanto, no alcanzaría a la validez del expediente autorizado ni podría dar lugar a otros efectos conexos". 
La literalidad de esta DA $14^{\mathrm{a}}$ permite entender que esta cláusula es de aplicación general (en especial, al emplear el término «entre otros»).

En todo caso, reparen que esta redacción, al posibilitar suavizar el compromiso de salvaguarda del empleo (DA $6^{\text {a }}$ RDLey $8 / 20$ ), permitiendo la extinción de los contratos temporales por cumplimiento del término o la realización de la obra o servicio, «matiza», a su vez, la interrupción de la duración de los contratos temporales afectados por un ERTE que establece el artículo 5 RDLey 9/20 y, de esta forma, «salva» el posible «desajuste» que la combinación de ambas normas suscitaba.

\subsubsection{Bonificación para el mantenimiento de la actividad de fijos discontinuos}

El artículo 13 RDLey 7/20 prevé medidas de apoyo a la prolongación del periodo de actividad de los trabajadores con contratos fijos discontinuos en los sectores de turismo y comercio y hostelería vinculados a la actividad turística (no aplicables a las Islas Baleares y Canarias - en las que ya se aplicaban las medidas derivadas del RDLey 12/19).

En concreto se establece lo siguiente:

"Las empresas, excluidas las pertenecientes al sector público, dedicadas a actividades encuadradas en los sectores del turismo, así como los del comercio y hostelería, siempre que se encuentren vinculadas a dicho sector del turismo, que generen actividad productiva en los meses de febrero, marzo, abril, mayo, junio y que inicien o mantengan en alta durante dichos meses la ocupación de los trabajadores con contratos de carácter fijos discontinuo, podrán aplicar una bonificación en dichos meses del 50 por ciento de las cuotas empresariales a la Seguridad Social por contingencias comunes, así como por los conceptos de recaudación conjunta de Desempleo, FOGASA y Formación Profesional de dichos trabajadores.

Lo dispuesto en este artículo será de aplicación desde el 1 de enero de 2020 hasta el día 31 de diciembre de 2020”.

\subsection{Medidas de fomento del empleo: la flexibilización laboral en el empleo agrario}

El objetivo principal del RDLey 13/20, de 7 de abril, por el que se adoptan determinadas medidas urgentes en materia de empleo agrario, es tratar de incrementar la oferta de mano de obra del sector agrario a través, principalmente, de la posibilidad de 
compatibilizar ciertas prestaciones con un contrato temporal sometido a término (hasta el 30 de junio 2020).

- Objetivo (artículo 1): Como expone su artículo 1, «tiene por objeto favorecer la contratación temporal de trabajadores en el sector agrario mediante el establecimiento de medidas extraordinarias de flexibilización del empleo, de carácter social y laboral, necesarias para asegurar el mantenimiento de la actividad agraria», siendo de aplicación temporal hasta el 30 de junio.

- Beneficiarios (artículo 2.1 y 2):

a. Personas en situación de desempleo o cese de actividad (y aunque este precepto no lo especifica, en virtud del artículo 3.1.d debe entenderse que con exclusión de los ceses de actividad que tengan su origen en la medida prevista en el artículo 17 RDLey 8/20).

b. Trabajadores cuyos contratos se hayan visto temporalmente suspendidos como consecuencia del cierre temporal de la actividad conforme a lo señalado en el artículo 47 ET, con exclusión de aquellas que tengan su origen en las medidas previstas en los ERTE ex artículos 22, 23 y 25 el RDLey 8/20.

c. Trabajadores migrantes cuyo permiso de trabajo concluya en el periodo comprendido entre la entrada en vigor del RD y el 30 de junio de 2020, cuya prórroga se determinará a través de instrucciones de la Secretaría de Estado de Migraciones.

d. Asimismo podrán acogerse los jóvenes nacionales de terceros países, que se encuentren en situación regular de entre los 18 y los 21 años.

e. Las personas cuyos domicilios se hallen próximos a los lugares en que haya de realizarse el trabajo.

En este sentido, se entiende que en todo caso existe proximidad cuando el domicilio de trabajador o el lugar en que pernocte temporalmente mientras se desarrolla la campaña esté en el mismo término municipal o en términos municipales limítrofes del centro de trabajo. Las comunidades autónomas podrán ajustar este criterio en función de la estructura territorial teniendo en cuenta el despoblamiento o la dispersión de municipios

- Compatibilidad de prestaciones (artículo 3): Se habilita la compatibilidad de este trabajo temporal con diversas prestaciones, con la excepción de aquellas que estén expresamente reconocidas en virtud del RDLey 8/20. En concreto, las retribuciones percibidas por la actividad laboral que se desempeñe al amparo de las medidas extraordinarias de flexibilización del empleo establecidas en el presente real decreto-ley serán compatibles: 
a. Con el subsidio por desempleo ex RD 5/1997, o con la renta agraria ex RD 426/2003.

b. Con las prestaciones por desempleo derivadas de la suspensión por CETOP ex artículo 47 ET, con exclusión de aquellas que tengan su origen en las medidas previstas en los artículos. 22, 23 y 25 el RDLey 8/20.

c. Con cualesquiera otras prestaciones por desempleo reguladas en el título III de la LGSS.

d. Con las prestaciones por cese de actividad motivadas por las causas previstas en el artículo 331 LGSS, con exclusión de aquellas que tengan su origen en la medida prevista en el artículo 17 RDLey 8/20.

e. Con cualquier otra prestación de carácter económico o cualquier otro beneficio o ayuda social, otorgada por cualquier Administración que sea incompatible con el trabajo, o que, sin serlo, como consecuencia de la percepción de ingresos por la actividad laboral se excederían los límites de renta señalados en la normativa correspondiente al tipo de prestación.

Por otra parte, según la DA $2^{\mathrm{a}}$, durante en el período comprendido desde la entrada en vigor del RDLey 13/20 hasta el 30 de junio de 2020 no será de aplicación el régimen de incompatibilidad previsto en el artículo 15 RD 625/1985 ni el régimen de incompatibilidades previsto en el artículo 342 LGSS, a los trabajadores contratados al amparo de lo previsto en RDLey 13/20.

- Incompatibilidades (artículo 3): Las retribuciones son incompatibles con:

- Las prestaciones económicas de Seguridad Social por incapacidad temporal, riesgo durante el embarazo y riesgo durante la lactancia natural.

- Las pensiones de incapacidad permanente contributiva, salvo los supuestos de compatibilidad previstos en la LGSS.

- Con la prestación por nacimiento y cuidado de menor de la Seguridad Social, si bien, salvo por lo que respecta al periodo obligatorio de la madre biológica a continuación del parto el periodo obligatorio, o la parte que restara del mismo, se podrá disfrutar desde el día siguiente a la finalización de las prestaciones previstas en el presente real decreto-ley.

- Ingresos y límites de rentas para prestaciones contributivas y no contributivas ( artículo 3): Los ingresos obtenidos por esta actividad laboral no se tendrán en cuenta a efectos de los límites de rentas establecidos para las prestaciones contributivas o no contributivas de la Seguridad Social, incluidos los complementos por mínimos de las pensiones contributivas. 
- Obligaciones del empresario (artículos 4 y 5.6): El empresario deberá asegurar en todo momento la disponibilidad de medios de prevención apropiados frente al COVID-19. Y, según el artículo 5.6 6, "El salario se abonará por transferencia bancaria en la cuenta indicada por el trabajador en el contrato suscrito con el empleador. En todo caso, la remuneración mínima que se debe aplicar, con independencia del sector donde proceda el trabajador, debe ser la que corresponda según Convenio Colectivo vigente que resulte de aplicación y en todo caso, el SMI recogido en el RD 231/20”.

- Tramitación (artículo 5): El artículo 5 establece las reglas específicas de tramitación. De las que, a continuación, destaco las que estimo más relevantes:

En primer lugar, se emplaza a las administraciones competentes y los agentes sociales promoverán la contratación de las personas que se encuentren en las circunstancias descritas, especialmente en cuanto a la proximidad (artículo 5.1).

Esta tramitación debe canalizarse a través de los servicios de empleo público autonómicos, quienes deben recibir las ofertas de empleo que deban cubrirse y que deben asegurarse del cumplimiento de los beneficiarios cumplen los requisitos anteriormente descritos (artículo 5.2)

Se prevé un listado de posibles criterios de prioridad a concretar por los servicios de empleo público autonómicos para el caso de que el número de demandantes de empleo supere la oferta disponible de trabajadores:

a. Personas en situación de desempleo o cese de actividad que no perciban ningún tipo de subsidio o prestación.

b. Personas en situación de desempleo o cese de actividad que perciban únicamente subsidios o prestaciones de carácter no contributivo

c. Personas en situación de desempleo o cese de actividad perceptores de subsidios por desempleo o prestaciones de carácter social o laboral.

d. Migrantes cuyos permisos de trabajo y residencia hayan expirado durante el periodo comprendido entre la declaración de estado de alarma y el 30 de junio de 2020.

e. Jóvenes nacionales de terceros países, que se encuentren en situación regular, entre los 18 y los 21 años.

En relación a estos criterios, no parece que sea posible añadir otros y parece que lo único que pueden establecer los servicios públicos de empleo es alterar el orden. 


\subsection{El permiso retribuido recuperable}

El permiso retribuido recuperable (en adelante, "PRR"), regulado en por el RDLey 10/20, es una de las medidas más controvertidas de las dictadas durante este período de emergencia. Personalmente estimo que, en la medida que (como se analizará), esta disposición no impide que se sigan planteando ERTE, puede concluirse que el objetivo primario que se persigue es esencialmente sanitario (y no tanto - o al menos, de forma predeterminada y directa - imputar el coste a las empresas).

A la hora de abordar el análisis el PRR, y a pesar de su denominación, a mi modo de ver, su naturaleza jurídica estaría a caballo de diversas instituciones: el permiso, la distribución irregular de la jornada e, incluso, el factum principis.

Por este motivo, en primer lugar, se procederá a la delimitación conceptual del «permiso ordinario» en su concepción «prototípica». A partir de este enfoque, se las implicaciones de la nueva regulación.

2.5.1. Delimitación conceptual de los permisos (y de la suspensión y la excedencia)

Los contornos conceptuales del permiso y su diferenciación con instituciones próximas (la suspensión y, de forma más lejana, la excedencia), plantea algunas controversias.

En denominador común es que en todas ellas (permiso, suspensión y excedencia) se produce un incumplimiento de, al menos, una de las prestaciones esenciales del contrato (la prestación de trabajo).

El principal problema al respecto es la deficiente precisión técnico-jurídica de la regulación positiva, pues, creo que no existe una correspondencia entre los términos empleados en el ET para referirse a cada institución y los efectos que se derivan de cada una de ellas (desfase, especialmente, visible en determinados supuestos de "excedencia", pero también con los "permisos" - artículo 23.1.c TRET).

Motivo por el que, a pesar de la denominación empleada, creo que debe tratarse de identificar y agrupar conceptualmente todos aquellos supuestos que participan de efectos jurídicos comunes. 
a. Sobre la suspensión

Empezando por la suspensión VIDA SORIA (1966: 251 y 261), ésta "es una vicisitud por la que puede atravesar el contrato, que en un determinado momento encuentra no cumplida la normal ejecución de las prestaciones objeto del mismo".

La suspensión provoca una cesación temporal de la ejecución del contrato, que desemboca en una liberación recíproca de las prestaciones fundamentales. Sin embargo, a pesar de ello, el ordenamiento jurídico inhabilita los cauces de funcionamiento contractual ordinarios, restringiendo temporalmente la posibilidad de extinguir el vínculo (RIVERO LAMAS, 1972: 183 y 184). En consecuencia, circunstancias aptas para justificar la resolución no despliegan su capacidad para dejar al contrato sin efectos y permanecen provisionalmente en estado latente.

Siguiendo con VIDA SORIA (1966: 254), la suspensión está vinculada a la acción resolutoria y, especialmente, a la excepción de contrato no cumplido ("exceptio non adipleti contractus").

Por lo tanto, puede afirmarse que el incumplimiento de lo convenido es consustancial a la suspensión (frente a otros planteamientos que entienden que es una modalidad de ejecución defectuosa del contrato). De modo que el retraso en el cumplimiento no afecta a la vigencia del vínculo, que permanece inalterable, al igual que el resto de obligaciones contractuales no afectadas por la circunstancia suspensiva.

Desde este punto de vista, y tomando como referencia los efectos jurídicos, puede entenderse que el principal efecto jurídico de la suspensión, genéricamente considerada, consiste en la liberación recíproca de las prestaciones esenciales del contrato. Por otro lado, el contrato de trabajo permanece vigente respecto del resto de prestaciones no afectadas por la suspensión. En todo caso, la suspensión no es retribuida, por lo que ni el trabajador debe prestar el trabajo ni el empresario abonar el salario. Finalizado el período suspensivo (la causa habilitante) el trabajador se reincorpora automáticamente a su puesto de trabajo, ostentando una "reserva de plaza". Así pues, se produce una cesación temporal de ciertos efectos del contrato.

En definitiva, la suspensión es un método jurídico-positivo ideado con una finalidad unívoca: prolongar la vida del contrato. Gráficamente, siguiendo a VIDA SORIA (1966: 256), "consiste en un endurecimiento del vínculo, haciéndolo a la vez flexible de tal modo que pueda soportar, sin quebrar su resistencia, situaciones de anormalidad que en su momento podían hacerlo desaparecer". 
b. Sobre la excedencia

En la excedencia, por su parte, también opera un incumplimiento de las prestaciones esenciales del contrato. Es decir, ni trabajador ni empresario cumplen las prestaciones a las que se habían obligado. No obstante, a diferencia de la suspensión, no queda garantizada la reincorporación automática del trabajador una vez cesada la causa que produjo la excedencia (no hay reserva de plaza). En estos casos, el trabajador sólo se le atribuye un derecho preferente al reingreso.

A partir de estos elementos, podemos afirmar que, a pesar de la denominación legal, deben calificarse como supuestos suspensivos, todos los supuestos a los que el ET se refiere como "excedencia", salvo la "excedencia voluntaria" prevista en el artículo 46.2 TRET y la "excedencia sindical" prevista en el artículo 46.4 TRET, porque en estos supuestos simplemente se reconoce un derecho preferente al reingreso. Mientras que en la suspensión (y el permiso) la continuidad en el empleo no está «amenazada», es claro que no ocurre lo mismo con la excedencia.

c. Sobre el permiso

El permiso (o interrupción), en cambio, se caracteriza por el hecho de que el trabajador está legalmente facultado para no realizar la prestación laboral durante un plazo de tiempo, manteniendo el derecho al cobro del salario.

En este sentido, siguiendo el criterio de la SAN 13 de junio 2018 (rec. 91/2018)

"Los permisos retribuidos, regulados en el artículo 37.3 ET, reconocen el derecho de los trabajadores a ausentarse del trabajo sin pérdida de sus retribuciones, cuando concurran los supuestos allí contemplados. Consiguientemente, son permisos causales, cuya finalidad es satisfacer determinadas necesidades de los trabajadores, como puede ser el matrimonio o, en su caso, nacimientos, hospitalizaciones, intervenciones quirúrgicas, o fallecimientos de familiares hasta determinado grado de afinidad".

En los permisos, a diferencia de la suspensión, no hay, propiamente, una reserva de puesto de trabajo. Así, por ejemplo, recientemente el TS (sentencia 30 de octubre 2019, rec. 1070/2017) y a propósito de las vacaciones, ha entendido que la ausencia por vacaciones no es una situación que describa propiamente una suspensión del contrato de trabajo con derecho a reserva de plaza. Se trata, en cambio de "una mera interrupción ordinaria de la prestación de servicios que no genera vacante reservada propiamente dicha". 
No obstante, como se ha apuntado, si se toma como referencia el parámetro de los efectos jurídicos, el Legislador también emplea el término «permiso» de forma «impropia». Y el artículo 23.1.c ET (al reconocer «una reserva de puesto de trabajo») es una buena muestra. Y, en el marco del Derecho comunitario, por ejemplo, también se recurre al término «permiso» 22.

Por otra parte, tengan en cuenta que no todos los permisos son «voluntarios», por ejemplo, en los casos de nacimiento, literalmente, se emplea el término «permiso obligatorio» de 6 semanas (Apartado 1.f del DT 13 ${ }^{\mathrm{a}} \mathrm{ET}$ ).

\section{i. Sobre los efectos del permiso: remuneración y recuperación}

En relación a la remuneración, la STS 6 de marzo 2012 (rec. 80/2011) afirma que, en materia de

"las licencias o permisos retribuidos, el artículo 37 ET no establece regla alguna sobre el cálculo de su remuneración (...) a falta de expresa norma legal, serán los términos del convenio colectivo los que determinen el cálculo de la remuneración correspondiente a los días de permiso o licencia"

Y concluye que:

"el convenio colectivo puede incidir en la remuneración de vacaciones y licencias y el análisis de conformidad del mismo respecto del mínimo indisponible que surge del mandato de la norma internacional exige que se incluyan los complementos salariales que constituye la contraprestación efectiva de la actividad laboral ordinaria".

A partir de esta doctrina, la STS 3 de diciembre 2019 (rec. 141/2018) puntualiza que aunque la propia negociación colectiva que es origen de un complemento salarial puede establecer las condiciones en las que se genera el derecho a su percepción, esta posibilidad no es ilimitada:

"Encuentra una excepción en aquellos supuestos en los que la exclusión del complemento, en determinadas clases de licencias y permisos, pudiera suponer una merma de la efectividad del principio de igualdad de mujeres y hombres".

22 Por ejemplo, en la Directiva (UE) 2019/1158 del Parlamento Europeo y del Consejo, de 20 de junio de 2019, relativa a la conciliación de la vida familiar y la vida profesional de los progenitores y los cuidadores, y por la que se deroga la Directiva 2010/18/UE del Consejo. 
De modo que entiende que la remuneración de los permisos y licencias del artículo 37 ET, debe comprender la totalidad de los complementos salariales en los supuestos del artículo 37.3 letras b) - excepto por fallecimiento; e) y f); así como en el del permiso de lactancia del artículo 37.4 ET. Incluidos los incentivos por productividad que hubiere devengado el trabajador en el caso de haber prestado servicio (de modo que un acuerdo colectivo no puede privar de su abono).

Por otra parte, en la STS 9 de diciembre 2009 (rec. 8/2008), en un supuesto relativo a conceptos salariales variables y vinculados a objetivos se entiende que

"es preciso entender que cualquier interpretación de la ausencia de regulación concreta de la retribución del permiso de lactancia, tanto en el Estatuto como en el Convenio, que implique pérdida económica para el trabajador, es contraria al espíritu de la ley. Por ello, el disfrute de este derecho nunca puede suponer una pérdida económica".

En relación a la recuperación, siguiendo la exposición de la STS 20 de diciembre 2019 (rec. 233/2018), la cuestión relativa a si un concreto permiso retribuido por asuntos particulares es recuperable, ha sido examinada por el Tribunal Supremo, existiendo resoluciones judiciales favorables y contrarias a dicha recuperación en función de las específicas circunstancias concurrentes en cada supuesto.

Así, en particular, ha valorado lo siguiente:

1. La regulación del permiso y de la jornada laboral establecida en el convenio colectivo o en el acuerdo aplicable.

2. La existencia de una práctica empresarial conforme a la cual el permiso retribuido no era recuperable, conforme al artículo 1282 del Código Civil: "Para juzgar de la intención de los contratantes, deberá atenderse principalmente a los actos de éstos, coetáneos y posteriores al contrato".

3. La interpretación de la norma colectiva realizada por el Tribunal de instancia, cuyo criterio prevalece sobre el del recurrente, salvo que aquella interpretación no sea racional ni lógica o ponga de manifiesto la notoria infracción de alguna de las normas que regulan la exégesis contractual.

A la luz de estos criterios,

- A favor de la recuperación de permisos retribuidos por asuntos particulares SSTS 29 de mayo 2007 (rec. 113/2006); 14 de marzo 2011 (rec. 
125/2010); 17 de mayo 2011 (rec. 147/2010); 26 de septiembre 2011 (rec. 744/2011); y 6 de junio 2017 (rec. 171/2016).

- En contra de la recuperación de dichos permisos SSTS 26 de abril 1995 (rec. 3448/1993); 5 de noviembre 2002 (rec. 1226/2001); 16 de octubre 2012 (rec. 269/2011); 9 de abril 2014 (rec. 76/2013); y 22 de abril 2016 (rec. 168/2015).

Así, por ejemplo, se ha entendido (STS 17 de mayo 2011, rec. 147/2010) que, no es admisible una configuración convencional que prevea lo siguiente:

"si por definición los permisos -causales o no-son potestativos para el trabajador, es claro que atender a su recuperación incrementando con carácter general -y obligatorio- la jornada diaria [15 minutos todos los viernes del año y dos días -24 y 31 de Diciembre- 45 minutos], comporta necesariamente que o bien todos los trabajadores deber hacer uso de ese permiso o -si no lo hacen- vean injustificadamente aumentada su jornada anual con el equivalente horario a dos jornadas de trabajo".

d. La doctrina no es pacífica en la distinción

De todos modos, volviendo a los aspectos conceptuales de estas tres instituciones (permiso, suspensión y excedencia) se trata de una cuestión que no es pacífica en la doctrina.

Un sector (encabezado por Pedrajas Moreno, 437, 447 y 448) entiende que no existe una distinción entre estas instituciones, sino que son envolturas formales ("especies de un género institucional que las integra") que responden a una naturaleza común, un género suspensivo único, fundado en la interrupción de la ejecución de la prestación del trabajador en base al principio de estabilidad. Descartado el carácter autónomo de cada una de ellas, la distinción entre la interrupción, la suspensión y la excedencia, partiendo de la lógica de la imputación de riesgos, bascula sobre las siguientes coordenadas: mayor o menor interés del legislador de proteger un bien social, y mayor o menor duración de la situación. Así, la interrupción se identifica con situaciones de corta duración que socialmente se estiman que precisan de protección. A partir de aquí, en función de la mayor duración o bien de la importancia del fundamento próximo se articularían la suspensión y la excedencia. Aunque, como afirma este autor, la "realidad normativa no encaja con estos esquema teóricos".

RAMÍREZ MARTÍNEZ (1994: 26 a 30), descartando ambos posicionamientos, concluye que "los intentos de determinar la naturaleza jurídica de la suspensión no son satisfactorios". Por un lado, sostiene que a pesar de que uno de los elementos que 
denota la existencia de una institución autónoma es la existencia de efectos comunes, ésta no puede definirse únicamente por sus efectos, sino por la existencia de una "misma matriz institucional, definida por una caracterización única". En este sentido, estima que la distinción de VIDA SORIA no es válida porque toma como referencia los efectos jurídicos que se derivan de cada una de ellas. Por otro lado, tampoco acepta la opción unitaria, porque precisamente no puede predicarse la existencia de efectos comunes.

\subsubsection{El permiso retribuido recuperable (PRR)}

El «permiso retribuido recuperable» («PRR»), según el artículo 2.1 RDLey 10/20, es de aplicación obligatoria a todas las personas trabajadoras que prestan servicios en aquellas actividades que no sean esenciales y se extenderá entre el lunes 30 de marzo hasta el jueves 9 de abril de 2020, ambos inclusive (esto es, 8 días laborables)23. Por otra parte, se prevé su recuperanción desde que finalice el estado de alarma hasta el 31 de diciembre 2020.

A mi modo de ver, creo que es importante destacar la imperatividad de la medida o, dicho de otro modo, la imposibilidad de pactar durante su vigencia una medida alternativa ( $\sin$ perjuicio, de que en el período de negociación se pueda acordar el método de recuperación -respetando, al menos, los límites que describe el RDLey 10/20 y -entiendo también- la naturaleza jurídica de instituciones afectadas).

Es importante advertir que la recuperación de las horas no trabajadas no es «obligatoria» (de hecho, como se apuntará, podría negociarse su recuperación parcial; y podrían darse circunstancias que materialmente o por limitaciones de carácter normativo hagan que no sea posible en el plazo establecido).

En este período de tiempo, los trabajadores quedarán exonerados de prestar sus servicios, si bien ( artículo 2.2) continuarán recibiendo retribución que les hubiera correspondido de estar prestando servicios con carácter ordinario, incluyendo salario base y complementos salariales.

23 No obstante, en virtud de la DT $1^{\text {a }}$ RDLey 10/20, se prevé la posibilidad de trabajar el 30 de marzo en los casos que "resulte imposible interrumpir de modo inmediato la actividad (...) con el único propósito de llevar a cabo las tareas imprescindibles para poder hacer efectivo el permiso retribuido recuperable sin perjudicar de manera irremediable o desproporcionada la reanudación de la actividad empresaria". 
a. Sobre la naturaleza jurídica

La naturaleza jurídica de esta figura es particularmente compleja24. Permítanme que comparta las opciones que estimo que serían posibles:

- Permiso («atípico»):

A la luz de todo lo expuesto, una institución que aglutine los conceptos «permiso», «retribuido», «obligatorio»y «recuperable», en principio, no encajaría con la idea «prototípica» de la institución del «permiso». En esencia, como se ha apuntado, el denominador común de todas estas «figuras» (suspensión y excedencia incluidas) es que se produce un incumplimiento de, al menos, una de las prestaciones esenciales del contrato (la prestación de trabajo). Y, en este caso, la recuperación («obligatoria») podría estar desvirtuando esta nota característica.

Sin embargo, como también se ha destacado, el Legislador está empleando estas categorías conceptuales de forma «impropia» (por ejemplo, artículo 23.1.c ET; o apartado 1.f DT 13 ${ }^{\mathrm{a}}$ ET; o Directiva 2019/1158) y, además, el propio Tribunal Supremo ha admitido en algunos permisos, y en función de su específica configuración, la posibilidad de que sean recuperados.

Por consiguiente, sin negar que el PRR es una figura absolutamente «atípica» (por las circunstancias en las que se formula), en mi modesta opinión, no puede afirmarse que tenga una configuración absolutamente «extraña» a la misma (al menos, tal y como se ha estado legislando e interpretando antes del RDLey 10/20).

- Distribución irregular:

El PRR, probablemente, también esté a caballo de la «distribución irregular»25. Aunque no puede identificarse plenamente con ella, especialmente, porque las condiciones para la recuperación está sometida a un acuerdo y podría no llevarse a cabo26.

24 CAlvo y Rodríguez-PIÑERo (2020), entienden que, en relación al PRR, se ha producido "una clara desnaturalización de una institución laboral al servicio de la salud pública".

25 De hecho, las reglas sobre la recuperación del PRR - art. 3.3 RDLey 10/20 - establecen que el período de preaviso previsto en el art. 34.2 ET opera como un límite mínimo que debe respetarse

26 ARAGón GómEZ (2020), entiende que se "se trata de una distribución irregular de la jornada con un régimen jurídico particular". Sobre la distribución irregular, pueden consultar las SSTS 11 de diciembre 2019 (rec. 147/2018); y 16 de abril 2014 (rec. 183/2013). 
De modo que el RDLey 10/20 estaría reconociendo una «especie» de «bolsa de horas» a «consumir» hasta el 31 de diciembre 2020.

- Factum Principis:

A mi entender, no puede descartarse que el propio RDLey 10/20 esté describiendo un supuesto de factum principis; y, por consiguiente, describa un supuesto de «fuerza mayor» y «diferenciado» del derivado de la alarma sanitaria (aunque «perteneciente» a la misma «cadena causal»).

La referencia genérica a ERTE que «sean autorizados» durante la vigencia del RDLey 10/20 ex artículo 1.2.c) no lo impide explícitamente.

Personalmente, creo que sería posible, especialmente, porque en este supuestos no media culpabilidad alguna en el empresario. En este sentido, les recuerdo que por factum principis puede entenderse (FERNÁNDEZ DOMÍNGUEZ, 1993: 105), "toda decisión del poder o de la autoridad pública imprevisible ole inevitable que recae en la esfera de la autonomía privada dificultando o imposibilitando el cumplimiento de las obligaciones asumidas por las partes". Entendiéndose por autoridad o poder público en su más amplio sentido (DE LA VILLA GIL, 1970: 106; y ORTIZA LALLANA, 1985: 104).

Así pues, la concesión del PRR obligatorio no impediría que las empresas solicitaran un ERTE por fuerza mayor alegando precisamente el RDLey 10/20.

No son vacaciones obligatorias.

La previsión de recuperación del PRR aleja la idea de que se trata de un período de «vacaciones».

b. Ámbito de aplicación subjetiva

i. Afectados

Según el artículo 1 RDLey 10/20, las personas trabajadoras por cuenta ajena que prestan servicios en empresas o entidades del sector público o privado, cuya actividad no ha sido paralizada por la declaración del estado de alarma establecida por el RD 463/20. 
También quedan afectados ( artículo 1.2.c RDLey 10/20) las personas que estén disfrutando de un ERTE de reducción de jornada (aunque sea «vertical» - lo que, sin duda, puede plantear disfuncionalidades destacables).

Además, debe tenerse en cuenta que también podrían quedar afectados los siguientes colectivos:

- Primero, ( artículo 5 RDLey 10/20) el Ministro de Sanidad, en su condición de autoridad competente delegada puede, modificar o especificar, mediante las órdenes necesarias, las actividades que se ven afectadas por el PRR y sus efectos;

- Segundo, (DT $3^{\text {a }}$ RDLey 10/20) el Ministerio de Política Territorial y Función Pública y los competentes en las comunidades autónomas y entidades locales quedan habilitados para dictar las instrucciones y resoluciones que sean necesarias para regular la prestación de servicios de los empleados públicos incluidos en el ámbito de aplicación EBEP, con el objeto de mantener el funcionamiento de los servicios públicos que se consideren esenciales.

Es decir, en la medida que tales «instrucciones» tienen por objeto «mantener el funcionamiento de los servicios esenciales», debe entenderse que los funcionarios públicos también se ven afectados por el PRR (de otro modo, no sería necesario establecer «instrucciones» con este propósito)27. El artículo 4 de la Orden SND/310/2020 confirmaría la sujeción de los empleados públicos al PRR.

Por otra parte, la aplicación del PRR a este colectivo podría plantear un trato diferenciado con respecto al personal del sector público que, por ejemplo, con anterioridad al RDLey 10/20, y en virtud de sus respectivos planes de contingencia y organización, estuvieran disfrutando de un permiso en virtud del artículo 48.j del EBEP (y, por consiguiente, no recuperable). En este sentido, no

27 En términos similares, GORDO GONZÁlez (2020). No obstante, el Presidente de la Comisión de Coordinación del Empleo Público ha publicado una "Nota Informativa" (no vinculante) defendiendo otro planteamiento (ver al respecto en el Blog de Anexpal, 2020). En contra también, JiMÉNEZ ASENSIO (2020). Una síntesis de las reacciones al respecto por parte de diversas Administraciones en TORRALBA (2020). Finalmente, el Ministerio de Política Territorial ha emitido una Nota informativa afirmando que el "Real Decreto-ley es exclusivamente una norma de carácter laboral que regula un permiso retribuido, recuperable y de carácter temporal, cuya finalidad es limitar al máximo la movilidad. Según esta interpretación, no incluye en su ámbito de aplicación al personal funcionario, ni al personal laboral de los departamentos ministeriales ni sus organismos públicos". 
creo que el RDLey 10/20 transforme la naturaleza jurídica del permiso que ya se estuviera disfrutando convirtiéndolo en el PRR.

Por otra parte, el contenido de esta DT $3^{\text {a }}$ RDLey 10/20 podría plantear algún desajuste con respecto al del artículo 1 RDLey 10/20, pues, los trabajadores de las entidades de derecho privado que forman parte del sector público también estén sujetos al EBEP (DA $1^{\text {a }}$ EBEP).

ii. Excluidos

La exclusión del PRR ( artículo 1.2 RDLey 10/20) es extensible a los siguientes colectivos:

- Los trabajadores (apartados a y b) de servicios calificados como esenciales y divisiones o líneas de producción cuya actividad se corresponda con los sectores calificados como esenciales (y que aparecen descritos en el Anexo del RDLey 10/20).

En general, puede decirse que el listado de colectivos es extenso y abarca actividades que, por lo general (al menos, en mi opinión), pueden ser calificadas como «esenciales»o, si lo prefieren «necesarias» en alguna fase de la cadena de los servicios esenciales que se pretenden mantener 28 .

De todas ellas (que no se reproducen por su extensión), debe destacarse el apartado 25 del Anexo, pues, en una cláusula de cierre de carácter general, habilita cualesquiera otras personas que "presten servicios que hayan sido considerados esenciales". El carácter pretérito de la «calificación» invita a pensar que ya lo habían sido (al no especificarse la disposición, resulta complejo poder concretarlas - reparen que en el apartado 1 del Anexo ya se cita al RD 463/20).

Por otra parte, se echa en falta, al menos desde el punto de vista laboral, que no se haya mención ni a los sindicatos ni a las asociaciones empresariales. No obstante, la Orden de 30 de marzo de 2020, del Ministerio de Sanidad, por la

\footnotetext{
28 En relación a los servicios vinculados a las víctimas de violencia de género, véase las especificidades previstas en el RDLey 12/2020; - En relación al apartado 5 del Anexo (industria manufacturera) pueden consultar la Nota Interpretativa para el Sector Industrial publicada por el Ministerio de industria, Comercio y Turismo; - En relación a los centros y servicios sanitarios, véase la Orden SND/310/2020, de 31 de marzo, por la que se establecen como servicios esenciales determinados centros, servicios y establecimientos sanitarios.
} 
que se establecen los criterios interpretativos para la aplicación del Real Decreto-Ley 10/2020, de 29 de marzo y el modelo de declaración responsable para facilitar los trayectos necesarios entre el lugar de residencia y de trabajo establece:

"Las actividades de representación sindical y patronal no están afectadas por las restricciones de movilidad contenidas en el Real Decreto 463/2020, de 14 de marzo, y en el Real Decreto-Ley 10/2020, de 29 de marzo, con el fin garantizar la asistencia y asesoramiento a personas trabajadoras $y$ empleadores".

- Los trabajadores afectados por un ERTE suspensivo efectivo o en trámite de solicitud o los que se vean afectados por un ERTE suspensivo autorizado durante la vigencia del PRR. En este sentido, a mi entender, deben entenderse comprendidos también los que ERTE aprobados por silencio administrativo (pues, no se está exigiendo una resolución expresa).

- Trabajadores de baja por IT o con el contrato suspendido por otras causas legalmente previstas.

- Las personas trabajadoras que puedan seguir desempeñando su actividad con normalidad mediante teletrabajo o cualquiera de las modalidades no presenciales de prestación de servicios.

No obstante, hay otros colectivos excluidos:

- En virtud del artículo 4, las empresas afectadas por el PRR, en caso de ser necesario, pueden "establecer el número mínimo de plantilla o los turnos de trabajo estrictamente imprescindibles con el fin de mantener la actividad indispensable. Esta actividad y este mínimo de plantilla o turnos tendrá como referencia la mantenida en un fin de semana ordinario o en festivos". Se trata, sin duda, de una disposición de contornos y control complejos.

- Como se ha expuesto, con carácter razonable a mi entender, en virtud de la DT $1^{\text {a }}$, se puede trabajar el lunes 30 de marzo en aquellos sectores incluidos en el Anexo si es "imposible interrumpir de modo inmediato la actividad (...) con el único propósito de llevar a cabo las tareas imprescindibles para poder hacer efectivo el permiso retribuido recuperable sin perjudicar de manera irremediable o desproporcionada la reanudación de la actividad empresaria". 
- Según la DT 2a , los trabajadores del ámbito del transporte que se encuentren realizando un servicio no incluido en el RDLey 10/20 en el momento de su entrada en vigor, iniciarán el permiso retributivo recuperable una vez finalizado el servicio en curso, incluyendo como parte del servicio, en su caso, la operación de retorno correspondientes.

- Según la DA 3 ${ }^{\text {a }}$, los jueces, fiscales, letrados de la Administración de Justicia y demás personal al servicio de la misma seguirán atendiendo las actuaciones procesales no suspendidas por el RD 463/20 con las adaptaciones que en su caso sean necesarias a la vista de lo dispuesto en el presente Real Decreto-Ley. Asimismo, continuarán prestando servicios el personal de Administración de Justicia que sea necesario para la prestación de servicios esenciales del Registro Civil conforme a las Instrucciones del Ministerio de Justicia.

- Según la DA 4a , el personal comprendido en el artículo 4 EBEP estará sometido a las instrucciones y resoluciones necesarias para determinar el régimen jurídico aplicable tanto en lo que se refiere al carácter esencial de sus servicios como a la organización concreta de los mismos.

- Según la DA 5a , también pueden seguir sus actividades los trabajadores de las empresas adjudicatarias de contratos de obras, servicios y suministros del sector público que sean indispensables para el mantenimiento y seguridad de los edificios y la adecuada prestación de los servicios públicos, incluida la prestación de los mismos de forma no presencial, todo ello sin perjuicio de lo establecido en el artículo 34 del RDLey 8/20.

Finalmente, téngase en cuenta que el RDLey 10/20 no hace mención alguna a los trabajadores autónomos ni a los TRADE (por lo que debe entenderse que quedan excluidos por no tener la condición de trabajadores por cuenta ajena). De hecho, este criterio ha quedado confirmado con respecto a los autónomos por la Orden de 30 de marzo de 2020 del Ministerio de Sanidad citada ( artículo 2)29.

A su vez, la norma no especifica qué sucede con los trabajadores que están disfrutando de una jornada irregular, o bien, que estén disfrutando de las vacaciones antes de la entrada en vigor del RDLey 10/20.

29 "El Real Decreto 463/2020, de 14 de marzo, solo afecta a los autónomos que prestan sus servicios en actividades suspendidas por la declaración del estado de alarma. Por su parte, el Real Decreto-ley 10/2020, de 29 de marzo, no resulta de aplicación a las personas trabajadoras por cuenta propia". 
- En relación con el primero de los casos, en uno de los borradores del RDLey 10/20 que circuló por las redes sociales, se preveía la exclusión del RDLey 10/20 a quienes estuvieran disfrutando de una jornada irregular. A mi modo de ver, debe seguirse un criterio similar al previsto para los casos de las personas que tienen el contrato suspendido, de modo que no se verían afectadas por el PRR.

- En relación a las vacaciones, en otro de los barradores que circuló por las redes sociales también se preveía la posibilidad de compensar los días de vacaciones coincidentes con el PRR (de algún modo, el permiso «transformaba» la naturaleza jurídica de las vacaciones, convirtiéndolas ex lege en PRR). Al no introducirse esta especificidad, a mi entender $-\mathrm{y}$ siguiendo el mismo criterio que anteriormente- debe entenderse que quedan excluidos del PRR y, por lo tanto, quienes se encuentren disfrutando de las vacaciones no podrán compensar, pues, no se les está aplicando el PRR.

iii. Vigencia del contrato y obligación de cotizar

En la medida que el RDLey 10/20 no hace indicación alguna a la cuestión relativa la vigencia del contrato (salvo el hecho de confirmar la percepción ordinaria del salario y la paralización de la actividad) debe entenderse que durante el PRR se aplica íntegramente el régimen ordinario de los permisos.

El contrato por consiguiente debe entenderse que el trabajador se encuentra en alta y existe obligación de cotizar. En este sentido, comparto con ARENAS GÓMEZ (2020) que esta situación «es equivalente a la situación de prestación efectiva de servicios»y, además debe cotizarse «por el importe de las retribuciones efectivamente percibidas».

Por otra parte, no parece que la interrupción de los contratos temporales afectados por un ERTE ex artículo 22 y 23 RDLey 8/20 que prevé el artículo 5 RDLey 9/20 sea aplicable a los contratos afectados por el PRR.

iv. Sanciones

Como se ha apuntado al inicio, reparen que no se prevé ninguna sanción específica en caso de incumplimiento del PRR por parte de las empresas, debiéndose entender que se aplica el régimen ordinario. 
En este sentido, recogiendo el criterio de MARTínEZ Aso (2020), puede entenderse que la LISOS

"asocia un tipo infractor para la transgresión de las normas en materia de permisos, el artículo 7.5, pero lo vincula a las normas de tiempo de trabajo referidas en los artículos 12, 23 y 34 a 38 del Estatuto de los Trabajadores, no a las del Real Decreto ley 10/2020. Está claro que la tipificación ni es imprecisa ni flexible, por lo que una interpretación extensiva no resultaría razonable. No hay que apuntarse al desánimo, el tipo infractor del artículo 7.10 de la norma sancionadora puede acoger sin dificultad la contravención de este permiso retribuido, ya que la empresa, durante el período del 30 de marzo al 9 de abril de 2020, está imponiendo a sus trabajadores condiciones de trabajo inferiores a las establecidas legalmente por imposibilitar el permiso retribuido recuperable generándoles un riesgo sanitario que podría agravar la propuesta de sanción".

c. Sobre la recuperación de las horas de trabajo

El régimen jurídico de la recuperación es el siguiente:

i. Período de recuperación

El período de recuperación será posible (artículo 3.1) desde el día siguiente a la finalización del estado de alarma y hasta el 31 de diciembre de 2020.

ii. Recuperación sometida a acuerdo (o, en su defecto, decisión de la empresa)

La recuperación de las horas de trabajo (artículo 3.2) deberá negociarse en un periodo de consultas abierto al efecto entre la empresa y la representación legal de las personas trabajadoras, que tendrá una duración máxima de 7 días (si no hubiera RLT en la empresa, se emplaza a los sindicatos más representativos del sector y, en su defecto, por 3 trabajadores de la empresa ex artículo 41.4 ET). La comisión representativa debe estar constituida en 5 días.

El acuerdo que se alcance (tras un proceso de negociación de buena fe, obtenidas las mayorías pertinentes y con la posibilidad de acudir al procedimiento de mediación o arbitraje habilitado), podrá establecer lo siguiente:

- Recuperar total o parcialmente las horas. 
- El preaviso mínimo con que la persona trabajadora debe conocer el día y la hora de la prestación de trabajo resultante (con el límite del periodo previsto en el artículo 34.2 ET).

- El periodo de referencia para la recuperación del tiempo de trabajo no desarrollado.

Si no se alcanza un acuerdo durante el período de consultas, la empresa notificará a las personas trabajadoras y a la comisión representativa, en el plazo de 7 días desde la finalización de aquel, la decisión sobre la recuperación de las horas de trabajo no prestadas durante la aplicación del presente permiso.

Por otra parte, el RDLey 10/20 no contiene ninguna regla específica sobre la recuperación para los empleados públicos.

iii. Limites a la recuperación (con acuerdo o sin)

En cualquier caso ( artículo 3.3), la recuperación de estas horas no podrá incumplir los siguientes límites:

- Los periodos mínimos de descanso diario y semanal previstos en la ley y el convenio colectivo,

- El plazo de preaviso inferior al recogido en el artículo 34.2 ET (que es de 5 días)

- La jornada máxima anual prevista en el convenio colectivo que sea de aplicación

- Los derechos de conciliación de la vida personal, laboral y familiar reconocidos legal y convencionalmente.

Entre las posibilidades de recuperación no creo que sea posible que el pacto incluya la calificación del PRR como un período de vacaciones. Por dos motivos, en primer lugar, porque si el PRR no ha podido afectar a quienes ya se encontraban de vacaciones, esta «impermeabilidad»-por decirlo de algún modo-, para ser coherentes, debería predicarse también «a la inversa». Además, creo que tendría dificultades para encajar con la naturaleza jurídica de un permiso y también tengo mis dudas que lo hiciera con la de las vacaciones (en este último caso, es difícil pensar que el propósito de las vacaciones se cumpla en unas condiciones de confinamiento obligatorio).

2.6. Protección y asistencia a víctimas de violencia de género y prevención de riesgos laborales 
El RDLey 12/20, en el marco de las medidas de protección y asistencia a las víctimas de violencia de género, declara ciertos servicios como esenciales en este ámbito a los efectos del RD 463/20 y el PRR ex RDL 10/20.

Y el artículo 5 dispone que

"1. Las personas trabajadoras que por razón de su actividad profesional tengan contacto directo con las víctimas y, en todo caso, quienes prestan sus servicios en centros de teleasistencia, emergencia o acogida, deben seguir las medidas de protección recomendadas por el Ministerio de Sanidad, según el nivel de riesgo al que están expuestos.

2. A efectos de lo anterior, y siempre que las disponibilidades así lo permitan, las Administraciones Públicas competentes, así como las empresas proveedoras de servicios, deberán dotar a las personas trabajadoras de los centros de los equipos de protección individual" 30 .

\subsection{Colaboración de empleadas y empleados públicos}

La DA $18^{a}$ RDLEY 11/20, prevé que las empleadas y empleados públicos en servicio activo que soliciten colaborar tanto en el ámbito de su administración de origen como en cualquier otra administración, en las áreas de carácter sanitario, sociosanitario, de empleo, para la protección de colectivos vulnerables y aquellas otras que requieran un refuerzo en materia de personal como consecuencia de la situación provocada por el COVID-19, seguirán devengando sus retribuciones por el organismo de origen, no suponiendo modificación de su situación administrativa o contrato de trabajo mientras dure la declaración de Estado de alarma.

La prestación del servicio se podrá llevar a cabo tanto de manera presencial como a través de modalidades no presenciales de trabajo, previa autorización de su superior jerárquico y comunicación al órgano competente en materia de personal.

\section{Medidas "prestacionales" y de apoyo a empleados, autónomos y empresas}

La necesidad de contener los efectos económicos y en el empleo provocados por la paralización en seco de la actividad económica de múltiples sectores, se han adoptado diversas medidas dirigidas (como expone la EM del RDLey 8/20) a "proteger y dar

30 En relación a las dificultades que para el cumplimiento de las medidas de prevención de riesgos laborales que la alarma sanitaria suscita véase, MORENO SOLANA (2020); y FERIA BASILIO (2020). 
soporte al tejido productivo y social para minimizar el impacto y lograr que, una vez finalizada la alarma sanitaria, se produzca lo antes posible un rebote en la actividad".

En este sentido, se ha reforzado la prestación por desempleo y se han creado subsidios dirigidos a atender a colectivos especialmente vulnerables y a nuevas situaciones de necesidad vinculadas a la pérdida del empleo, así como a atender diversas contingencias vinculadas con la salud (3.1)31.

También se han articulado un conjunto de medidas, en el fondo, dirigidas (según la EM del RDLey 11/20) a "apoyar la actividad económica con medidas de liquidez y flexibilidad dirigidas a aliviar los costes para las empresas" y también para paliar los efectos del cese de actividad y de los efectos de los ERTE por fuerza mayor (3.2).

\subsection{Medidas dirigidas a empleados}

3.1.1. Desempleo en caso de suspensión o reducción de jornada por fuerza mayor o CETOP

El artículo 25 RDLey 8/20 está dirigido a agilizar la tramitación y abono de prestaciones por desempleo provocadas por un ERTE por fuerza mayor o CETOP derivados del estado de alarma32.

En este sentido, puede hacerse una distinción entre las condiciones y para el reconocimiento de la prestación y el procedimiento habilitado para hacer la solicitud.

\section{i. Régimen jurídico}

31 En este sentido, la DA $7^{\text {a }}$ RDLey $11 / 20$ prevé la posibildad de destinar los ingresos derivados de la cotización por formación profesional obtenidos en el ejercicio 2020, podrán destinarse también a la financiación de cualquiera de las prestaciones y acciones del sistema de protección por desempleo definidas en el art. 265 LGSS. Una síntesis de estas medidas en TALÉNS VISCONTI (2020). Por otra parte, la DA $3^{\text {a }}$ RDLey 13/20 establece un conjunto de medidas extraordinarias de simplificación para la tramitación de los procedimientos que permitan a las entidades gestoras de la Seguridad Social resolver de forma provisional en materia de prestaciones de la Seguridad Social. Y la DA 4 ${ }^{\text {a }}$ RDLey 13/20 hace lo propio en aras a simplificar la tramitación de los procedimientos que permitan al SEPE y al ISM resolver de forma provisional las solicitudes de prestaciones por desempleo presentadas por los ciudadanos.

32 Finalmente, no se ha incluido la limitación de la cuantía de la prestación de desempleo que aparecía en el borrador que circuló en las redes con anterioridad a su publicación oficial. Por otra parte, puede acceder a las Instrucciones provisionales del SEPE para la aplicación de estas reglas relativas a la prestación por desempleo aquí. Por otra parte, según la DT $1^{\mathrm{a}}$ RDLey 8/20 (redactada según la DF $1^{\mathrm{a}}$ RDLey 9/20), estas medidas "serán de aplicación a los afectados por los procedimientos de suspensión de contratos y reducción de jornada comunicados, autorizados o iniciados, con anterioridad a la entrada en vigor de este real decreto ley, siempre que deriven directamente del COVID-19". 
En concreto, en los supuestos en que la empresa decida la suspensión de contratos o la reducción temporal de la jornada de trabajo por las causas previstas en el artículo 47 ET, con base en las circunstancias extraordinarias reguladas en el RDLey 8/20, el citado artículo 25 prevé el percibo de la prestación de desempleo con estas condiciones:

- No se requiere un período de ocupación cotizada mínimo necesario.

- Reconocimiento prestación contributiva por desempleo aunque se carezca del período de ocupación cotizada mínimo necesario para ello.

- No computar el tiempo en que se perciba la prestación por desempleo de nivel contributivo que traiga su causa inmediata de las citadas circunstancias extraordinarias, a los efectos de consumir los períodos máximos de percepción establecidos.

- Se tiene derecho a esta prestación tanto si en el momento de la adopción de la decisión empresarial tuvieran suspendido un derecho anterior a prestación o subsidio por desempleo como si se carece del período mínimo de ocupación cotizada para causar derecho a prestación contributiva, o no hubiesen percibido prestación por desempleo precedente.

En todo caso, se reconocerá un nuevo derecho a la prestación contributiva por desempleo, con las siguientes especialidades respecto a la cuantía y duración:

a. La base reguladora de la prestación será la resultante de computar el promedio de las bases de los últimos 180 días cotizados o, en su defecto, del período de tiempo inferior, inmediatamente anterior a la situación legal de desempleo, trabajados al amparo de la relación laboral afectada por las circunstancias extraordinarias que han originado directamente la suspensión del contrato o la reducción de la jornada de trabajo.

b. La duración de la prestación se extenderá hasta la finalización del período de suspensión del contrato de trabajo o de reducción temporal de la jornada de trabajo de las que trae causa

- Según el artículo 25.6 RDLey 8/20, las prestaciones por desempleo percibidas por los trabajadores fijos discontinuos y por aquellos que realizan trabajos fijos y periódicos que se repiten en fechas ciertas, que hayan visto suspendidos sus contratos de trabajo como consecuencia del impacto del COVID-19 durante 
periodos que, en caso de no haber concurrido dicha circunstancia extraordinaria, hubieran sido de actividad, podrán volver a percibirse, con un límite máximo de 90 días, cuando vuelvan a encontrarse en situación legal de desempleo.

Para determinar el periodo que, de no haber concurrido esta circunstancia, hubiera sido de actividad laboral, se estará al efectivamente trabajado por el trabajador durante el año natural anterior en base al mismo contrato de trabajo. En caso de ser el primer año, se estará a los periodos de actividad de otros trabajadores comparables en la empresa. Esta medida se aplicará al mismo derecho consumido, y se reconocerá de oficio por la Entidad Gestora cuando el interesado solicite su reanudación33.

- Y, según el artículo 26 RDLey 8/20, si por motivos de limitación de la movilidad derivados de la situación de alarma que atañan al funcionamiento de los servicios públicos cuya actuación afecte a la gestión de la protección por desempleo, la presentación de las solicitudes de alta inicial o reanudación de la prestación y el subsidio por desempleo realizada fuera de los plazos establecidos legalmente, no implicará que se reduzca la duración del derecho a la prestación correspondiente.

- Prórroga del subsidio por desempleo y a la declaración anual de rentas.

El artículo 27 RDLey 8/20 prevé que en el caso de que por motivos de limitación de la movilidad derivados de la situación de alarma o que atañan al funcionamiento de los servicios públicos cuya actuación afecte a la gestión de la protección por desempleo, el SEPE y, en su caso, el Instituto Social de la Marina, podrán adoptar las siguientes medidas:

a. Suspender la aplicación de lo dispuesto en el segundo párrafo del artículo 276.2 del texto refundido de la Ley General de la Seguridad Social, autorizando a la entidad gestora para que pueda prorrogar de oficio el derecho a percibir el subsidio por desempleo en los supuestos sujetos a la prórroga semestral del derecho, a efectos de que la falta de solicitud no comporte la interrupción de la percepción del subsidio por desempleo ni la reducción de su duración.

33 En este sentido, el apartado 18 de la DF $1^{\text {a }}$ (que modifica el apartado $2^{\circ}$ de la DT $1^{\text {a }}$ RDLey $8 / 20$ ) ha establecido que esta medida "será de aplicación a los trabajadores que hayan visto suspendida su relación laboral con anterioridad a la fecha de entrada en vigor de ese Real Decreto-ley, siempre que dicha suspensión sea consecuencia directa del COVID-19". 
b. Suspender la aplicación de lo dispuesto en el tercer párrafo del artículo 276.3, de modo que, en el caso de los beneficiarios del subsidio para mayores de cincuenta y dos años no se interrumpirá el pago del subsidio y de la cotización a la Seguridad Social aun cuando la presentación de la preceptiva declaración anual de rentas se realice fuera del plazo establecido legalmente.

\section{ii. Procedimiento de sol· licitud}

En relación al procedimiento de solicitud, debe estarse a las reglas previstas en el artículo 3 y la DA $3^{\text {a }}$ RDLey 9/20 establecen nuevas reglas relativas a la prestación por desempleo:

Inicio del reconocimiento: En concreto, se establece que el reconocimiento de la prestación contributiva "se iniciará mediante una solicitud colectiva presentada por la empresa ante la entidad gestora de las prestaciones por desempleo, actuando en representación de aquéllas".

Obligación de información: Esta solicitud debe ir acompañada con la aportación de un conjunto de informaciones, segmentada por cada centro de trabajo afectado.

Nombre o razón social de la empresa, domicilio, número de identificación fiscal y código de cuenta de cotización a la Seguridad Social al que figuren adscritos los trabajadores cuyas suspensiones o reducciones de jornada se soliciten.

a. Nombre y apellidos, número de identificación fiscal, teléfono y dirección de correo electrónico del representante legal de la empresa.

b. Número de expediente asignado por la autoridad laboral.

c. Especificación de las medidas a adoptar, así como de la fecha de inicio en que cada una de las personas trabajadoras va a quedar afectada por las mismas.

d. En el supuesto de reducción de la jornada, determinación del porcentaje de disminución temporal, computada sobre la base diaria, semanal, mensual o anual.

e. A los efectos de acreditar la representación de las personas trabajadoras, una declaración responsable en la que habrá de constar que se ha obtenido la autorización de aquellas para su presentación.

f. La información complementaria que, en su caso, se determine por resolución de la Dirección General del Servicio Público de Empleo Estatal. 
Por otra parte, se emplaza a la empresa a comunicar "cualesquiera variaciones en los datos inicialmente contenidos en la comunicación, y en todo caso cuando se refieran a la finalización de la aplicación de la medida".

Plazo de comunicación: Esta comunicación (remitida a través de medios electrónicos y en la forma que se determine por el SEPE) debe remitirse en el plazo de 5 días, a computar según las siguientes situaciones:

- desde la solicitud del ERTE en los casos de fuerza mayor ex artículo 22 RDLey $8 / 20$;

- desde la fecha en que la empresa notifique a la autoridad laboral competente su decisión en el caso de ERTE por CETOP ex artículo 23 RDLey 8/20; o

- para las solicitudes anteriores a la entrada en vigor del RDLey 9/20 (debe entenderse de cualquier ERTE), a partir de la misma fecha.

Incumplimiento de la comunicación: La no transmisión de esta comunicación es considerada conducta constitutiva de la infracción grave prevista en el artículo 22.13 LISOS.

iii. Fecha de efectos de la situación de desempleo

La DA $3^{\text {a }}$ RDLey 9/20 concreta la fecha de efectos de la situación por desempleo, distinguiendo entre ERTE por fuerza mayor (la fecha del hecho causante) y por CETOP (fecha coincidente o posterior a la de la comunicación de la empresa a la autoridad laboral la decisión adoptada).

Por otra parte, la causa y fecha de efectos de la situación legal de desempleo deberán figurar, en todo caso, en el certificado de empresa, que se considerará documento válido para su acreditación 34.

iv. Sanciones

La DA $2^{a}$ RDLey 9/20 advierte de la imposición de la "correspondientes sanciones" ex LISOS en el caso de que la solicitud empresarial contenga "falsedades o incorrecciones en los datos facilitados" y, en particular "cuando den lugar a prestaciones que no debieran haberse producido".

34 Puede acceder a las Instrucciones provisionales del SEPE para la aplicación de estas reglas relativas a la prestación por desempleo aquí. 
El reconocimiento indebido de prestaciones a la persona trabajadora por causa no imputable a la misma,

"dará lugar a la revisión de oficio del acto de reconocimiento de dichas prestaciones. En tales supuestos, y sin perjuicio de la responsabilidad administrativa o penal que legalmente corresponda, la empresa deberá ingresar a la entidad gestora las cantidades percibidas por la persona trabajadora, deduciéndolas de los salarios dejados de percibir que hubieran correspondido, con el límite de la suma de tales salarios".

Disposición que debe complementarse con el contenido de la DA 4ª RDLey 9/20 que establece que

"En los supuestos en los que la entidad gestora apreciase indicios de fraude para la obtención de las prestaciones por desempleo, lo comunicará a la Inspección de Trabajo y Seguridad Social a los efectos oportunos".

\subsubsection{Subsidio de desempleo excepcional por fin de contrato temporal}

El artículo 33 RDLey 11/20 prevé un subsidio especial para los trabajadores con contrato temporal que carezcan de de la cotización necesaria para acceder a otra prestación o subsidio si carecen de las rentas previstas en el artículo 275 LGSS.

Además, este requisito, el régimen jurídico es el siguiente:

- Beneficiarios: personas a quienes se les haya extinguido un contrato de duración determinada (incluidos los contratos de interinidad, formativos y de relevo) de, al menos, dos meses de duración.

Reparen que el reconocimiento de este subsidio confirma que la interrupción de la duración de los contratos temporales que prevé el artículo 5 del RDLey 9/20, anteriormente expuesta, sólo es aplicable a las situaciones que se haya reconocido un ERTE suspensivo en virtud de los artículos. 22 y 23 RDLey 8/20.

- Incompatibilidad: Este subsidio es incompatible con la percepción de cualquier renta mínima, renta de inclusión, salario social o ayudas análogas concedidas por cualquier Administración Pública.

- Cuantía: una ayuda mensual del $80 \%$ del IPREM mensual vigente. 
- Duración: 1 mes, ampliable si así se determina por RDLey.

- Normas transitorias y retroactividad: la DT $3^{\mathrm{a}}$ RDLey $11 / 20$ prevé el derecho al subsidio se extiende a los hechos causantes que se hayan producido con anterioridad a su entrada en vigor, siempre que éstos se hubieran producido con posterioridad a la entrada en vigor del RD 463/20.

Por otra parte, la misma DT $3^{\mathrm{a}}$ establece lo siguiente:

“2. El Servicio Público de Empleo Estatal establecerá en el plazo de un mes, a partir de la entrada en vigor del presente real decreto-ley, el procedimiento para la tramitación de solicitudes, que determinará los formularios, sistema de tramitación (presencial o telemático) y el plazo máximo para su presentación.

3. Las solicitudes serán presentadas en el plazo máximo de veinte días desde la aprobación, por parte del Servicio Público de Empleo Estatal, del procedimiento de tramitación de solicitudes".

3.1.3. Subsidio extraordinario por falta de actividad para las personas integradas en el Sistema Especial de Empleados de Hogar

El contenido de este subsidio está regulado en los artículos. 31 y 32 RDLey 11/20. Y su régimen jurídico es el siguiente:

- Beneficiarios: personas que estando de alta en el Sistema Especial de Empleados del Hogar del Régimen General de la Seguridad Social antes la entrada en vigor del RD 463/20 se encuentren en alguna de las siguientes situaciones:

- Hayan dejado de prestar servicios, total o parcialmente, con carácter temporal, a fin de reducir el riesgo de contagio, por causas ajenas a su voluntad, en uno o varios domicilios y con motivo de la crisis sanitaria del COVID-19.

- Se haya extinguido su contrato de trabajo por la causa de despido recogida en el artículo 49.1.k del ET

- Se haya extinguido el contrato por el desistimiento del empleador o empleadora ex artículo 11.3 RD 1620/2011 con motivo de la crisis sanitaria del COVID-19.

- Acreditación hecho causante: cabe hacerlo de dos modos: 
- A través de una declaración responsable, firmada por la persona empleadora o personas empleadoras, respecto de las cuales se haya producido la disminución total o parcial de servicios.

- En caso de extinción del contrato, por medio de carta de despido, comunicación del desistimiento de la empleadora o empleador, o documentación acreditativa de la baja en el Sistema Especial de Empleados del Hogar.

\section{- Cuantía del subsidio.}

Base reguladora: base de cotización del empleado de hogar correspondiente al mes anterior al hecho causante, dividida entre 30. Si fueran varios los trabajos desempeñados en este sistema especial, se calculará sobre cada uno de los distintos trabajos que hubieran dejado de realizarse.

Cuantía: $70 \%$ de la base reguladora, sin que pueda ser superior al SMI, excluida la parte proporcional de las pagas extraordinarias.

Cuantía en caso de pérdida parcial: la cuantía del subsidio indicada se percibe en proporción directa al porcentaje de reducción de jornada experimentada.

Cuantía en caso de varios trabajos desempeñados: la suma del $70 \%$ de la base reguladora de cada uno de los trabajos perdidos o la proporción de la jornada reducida en cada uno de ellos sin que pueda superarse el SIM.

Si la cuantía total del subsidio, previamente a la aplicación de dichos porcentajes, alcanzara el importe del SMI, excluida la parte proporcional de las pagas extraordinarias, se prorrateará dicho importe entre todos los trabajos desempeñados atendiendo a la cuantía de las bases de cotización durante el mes anterior al hecho causante de cada uno de ellos, aplicándose a las cantidades así obtenidas el porcentaje de reducción de jornada que haya experimentado la persona trabajadora en la actividad correspondiente.

- Periodicidad de la percepción: percepción mensual desde la fecha del nacimiento del derecho (esto es, la fecha que aparezca en la declaración responsable cuando el hecho causante consista en la reducción de la actividad), o la fecha de baja en la Seguridad Social, en el caso del fin de la relación laboral.

- Compatibilidades del subsidio: con las percepciones derivadas de las actividades por cuenta propia o por cuenta ajena que se estuvieran desarrollando en el momento de su devengo, incluyendo las que determinan el alta en el Sistema Especial de los 
Empleados de Hogar, siempre que la suma de los ingresos derivados del subsidio y el resto de actividades no sea superior al SMI.

- Incompatibilidades del subsidio: con el subsidio por IT y con el PRR ex RDLey $10 / 20$.

- Normas transitorias y retroactividad: la DT $3^{\mathrm{a}}$ RDLey 11/20 prevé el derecho al subsidio se extiende a los hechos causantes que se hayan producido con anterioridad a su entrada en vigor, siempre que éstos se hubieran producido con posterioridad a la entrada en vigor del RD 463/220.

Por otra parte, la misma DT $3^{\mathrm{a}}$ establece lo siguiente:

“2. El Servicio Público de Empleo Estatal establecerá en el plazo de un mes, a partir de la entrada en vigor del presente real decreto-ley, el procedimiento para la tramitación de solicitudes, que determinará los formularios, sistema de tramitación (presencial o telemático) y el plazo máximo para su presentación.

3. Las solicitudes serán presentadas en el plazo máximo de veinte días desde la aprobación, por parte del Servicio Público de Empleo Estatal, del procedimiento de tramitación de solicitudes".

3.1.4. Compatibilidad del subsidio por cuidado de menor y prestación por desempleo o cese de actividad durante la permanencia del estado de alarma

La DA $22^{\mathrm{a}}$ RDLey 11/20 prevé que durante el estado de alarma el subsidio por cuidado de menores afectados por cáncer u otra enfermedad grave, que vinieran percibiendo los trabajadores por cuenta ajena a 14 de marzo de 2020, no se verá afectado por la suspensión del contrato y reducción de jornada que tengan su causa en lo previsto en los artículos 22 y 23 RDLey 8/20.

En estos casos, el expediente de regulación temporal de empleo que tramite el empresario, ya sea por suspensión de contratos o reducción temporal de la jornada de trabajo, solo afectara al trabajador beneficiario de este subsidio en la parte de la jornada no afectada por el cuidado del menor.

Será, por tanto, compatible el percibo del subsidio por cuidado de menores afectados por cáncer u otra enfermedad grave, con la percepción de la prestación por desempleo que como consecuencia de la reducción de la jornada, afectada por un expediente de regulación temporal de empleo, pudiera tener derecho a percibir. A tal efecto, la 
empresa al tiempo de presentar la solicitud, indicará las personas que tengan reducida la jornada de trabajo como consecuencia de ser titular del subsidio por cuidado de menores afectados por cáncer u otra enfermedad grave, señalando la parte de la jornada que se ve afectada por el expediente de regulación temporal de empleo. Durante el tiempo que permanezca el estado de alarma no existirá obligación de cotizar, teniéndose el periodo por cotizado a todos los efectos.

Esta medida, también es aplicable a los trabajadores autónomos que vinieran percibiendo el subsidio por cuidado de menores afectados por cáncer u otra enfermedad grave a 14 de marzo de 2020.

\subsubsection{Incapacidad temporal en situación excepcional de confinamiento total}

El artículo 5 RDLey 6/20, con carácter excepcional y al objeto de promover la salud pública, considera como situación asimilada a accidente de trabajo de los periodos de aislamiento o contagio de las personas trabajadoras como consecuencia del virus COVID-1935.

No obstante, en virtud de la Disp. Derogatoria Única RDLey 13/20, se deroga la DA $21^{\text {a }}$ del RDLey 11/20 que complementaba las reglas relativas a la incapacidad temporal en situación excepcional de confinamiento total previstas en el artículo 5 RDLey 6/20 y, en virtud de la DF $1^{\text {a }}$ RDLey 13/20 se establece una nueva redacción del este precepto.

El régimen jurídico vigente es el siguiente:

- Beneficiarios: Podrá causar derecho a esta prestación la persona trabajadora por cuenta propia o ajena que se encuentre en la fecha del hecho causante en situación de alta en cualquiera de los regímenes de Seguridad Social.

- Hecho causante: estableciéndose una amplia extensión de esta institución36, puede accederse a la prestación en las situaciones siguientes:

- Se considerarán, con carácter excepcional, situación asimilada a accidente de trabajo, exclusivamente para la prestación económica de IT del sistema de Seguridad Social, aquellos periodos de aislamiento o contagio de las personas

35 No obstante, téngase en cuenta que, con carácter previo, se dictó el Criterio 2/2020 de la Dirección General de Ordenación de la Seguridad Social de 26 de febrero y el Criterio 3/2020 de la Dirección General de Ordenación de la Seguridad Social de 9 de marzo de 2020. Extensamente al respecto y sobre la afectación de la alarma sanitaria sobre la IT véase, CALVO GALLEGO $(2020,3)$.

36 En opinión de CALVO GALLEGO $(2020,3)$ esta extensión ha desnaturalizado esta institución. 
trabajadoras provocados por el virus COVID-19, salvo que se pruebe que el contagio de la enfermedad se ha contraído con causa exclusiva en la realización del trabajo ex artículo 156 LGSS, en cuyo caso será calificada como accidente de trabajo.

- Con el mismo carácter excepcional, con efectos desde el inicio de la situación de restricción de la salida del municipio donde tengan el domicilio, y mediante el correspondiente parte de baja, se extenderá esta protección a aquellos trabajadores que se vean obligados a desplazarse de localidad para prestar servicios en las actividades no afectadas por el RD 463/20, siempre que por la autoridad competente se haya acordado restringir la salida de personas del municipio donde dichos trabajadores tengan su domicilio y les haya sido denegada de forma expresa la posibilidad de desplazarse por la autoridad competente, no puedan realizar su trabajo de forma telemática por causas no imputables a la empresa para la que prestan sus servicios o al propio trabajador y no tengan derecho a percibir ninguna otra prestación pública.

La fecha del hecho causante será la fecha en la que se acuerde el aislamiento, restricción o enfermedad del trabajador, sin perjuicio de que el parte de baja se expida con posterioridad a esa fecha.

- Acreditación: La acreditación del acuerdo de restricción de la población donde se tiene el domicilio y la denegación de la posibilidad de desplazamiento se realizará mediante certificación expedida por el ayuntamiento del domicilio ante el correspondiente órgano del servicio público de salud. De igual forma, la imposibilidad de realización del trabajo de forma telemática se acreditará mediante una certificación de la empresa o una declaración responsable en el caso de los trabajadores por cuenta propia ante el mismo órgano del servicio público de salud.

- Duración: La duración de esta prestación excepcional vendrá determinada por el parte de baja y la correspondiente alta. En los casos de restricción en las salidas del municipio donde tengan el domicilio, de tratarse de las personas trabajadoras por cuenta ajena ex artículo 1 RDLey 10/20 que regula el permiso retribuido recuperable, se expedirá un parte de baja con efectos desde la fecha de inicio de la restricción y un parte de alta con efectos de 29 de marzo de 2020.

De tratarse de trabajadores por cuenta propia o autónomos el derecho a la prestación comenzará con el parte de baja desde la fecha de inicio de la restricción y durará hasta la fecha de finalización de la restricción. 
- Incompatibilidad: Este subsidio por incapacidad temporal es incompatible con el derecho a una prestación de la Seguridad Social, incluida la incapacidad temporal por contingencias comunes o profesionales.

- Mutualismo administrativo: Por otra parte, en virtud del artículo 11 RDLey 7/20, se ha extendido un régimen con reglas similares para las personas incluidas en el mutualismo administrativo.

3.1.6. Efectos de la compatibilidad de la pensión de jubilación con el nombramiento como personal estatutario

La DA $15^{\text {a }}$ RDLey $11 / 20$ reconoce el derecho de los profesionales sanitarios realizados al amparo de la Orden SND/232/20 que se reincorporen al servicio activo tendrán derecho a percibir el importe de la pensión de jubilación que estuvieran percibiendo al tiempo de la incorporación al trabajo, en cualquiera de sus modalidades, incluido en su caso, el complemento a mínimos.

Se les aplicarán, en concreto, las siguientes reglas:

- No les será de aplicación lo previsto en los artículos 213 y 214 del Real Decreto Legislativo 8/2015, de 30 de octubre, por el que se aprueba el texto refundido de la Ley General de la Seguridad Social.

- El beneficiario tendrá la consideración de pensionista a todos los efectos.

- Además (según la redacción dada por la DF $3^{\text {a }}$ del RDLey 13/20 a la DA 15ª RDLey 11/20), durante la realización de este trabajo por cuenta ajena compatible con la pensión de jubilación, las comunidades autónomas o, en su caso, el Instituto Nacional de Gestión Sanitaria (INGESA), y los trabajadores están sujetos a la obligación de afiliación, alta, baja, variación de datos (ex artículo 16 LGSS) y a la obligación de cotizar (ex artículos. 18 y 19 LGSS), no siendo de aplicación lo dispuesto en el artículo 153 LGSS. Y, por otra parte, durante la realización de este trabajo, estarán protegidos frente a todas las contingencias comunes y profesionales, siempre que reúnan los requisitos necesarios para causarlas, siendo de aplicación el régimen de limitación de las pensiones, incompatibilidades y el ejercicio del derecho de opción, previstos la LGSS.

La protección de estos trabajadores, con ocasión o por consecuencia del trabajo desempeñado, consistirá: 
a. Cuando se expida un parte de baja médica calificada como accidente de trabajo, causarán derecho a la correspondiente prestación de incapacidad temporal derivada de accidente de trabajo que será compatible con el percibo de la pensión de jubilación que vinieran percibiendo al tiempo de su incorporación.

b. Cuando se expida un parte de baja médica calificada de enfermedad común, y siempre que acredite las cotizaciones exigidas en la letra a) del artículo 172 LGSS, causarán derecho a la correspondiente prestación de incapacidad temporal derivada de contingencias comunes que será compatible con el percibo de la pensión de jubilación que vinieran percibiendo al tiempo de su incorporación.

c. Cuando fueran declarados en situación de incapacidad permanente, podrán optar por continuar con el percibo de la pensión de jubilación o por beneficiarse de la correspondiente pensión de incapacidad permanente derivada de accidente de trabajo.

d. Cuando los profesionales jubilados falleciesen con ocasión o por consecuencia del trabajo desempeñado por dicha reincorporación, podrán causar las correspondientes prestaciones de muerte y supervivencia derivadas de accidente de trabajo.

Finalmente, reparen que en la exposición de motivos se indica que «Esta disposición establece cómo se ha de llevar a cabo la compatibilidad, cuál es el alcance de la protección social y cómo debe realizarse la cotización por parte del empresario y del trabajador durante el tiempo que permanezca en este régimen de compatibilidad».

Sin embargo, en la DA $15^{\text {a }}$ no se establecen las reglas relativas a la cotización.

3.1.7. Licencias y abono de retribuciones a los mutualistas de MUFACE y MUGEJU en situación de IT durante la vigencia del estado de alarma

La DA $5^{\mathrm{a}}$ del RDLey 13/20 establece un conjunto de reglas que deben tener en cuenta los órganos de personal respecto de los funcionarios mutualistas de MUFACE y de MUGEJU que se encuentren o iniciasen la situación de incapacidad temporal, en función de si la IT se inició con anterioridad o posterioridad a la declaración del estado de alarma.

En concreto: 
1. Si la incapacidad temporal se inició con anterioridad a la declaración del estado de alarma:

a. Para los mutualistas de MUFACE que no hayan alcanzado el día $91 .^{\circ}$ de la situación de incapacidad temporal, los órganos de personal:

i. Continuarán emitiendo licencias por enfermedad aun cuando no dispongan del parte de baja acreditativo del proceso patológico y la asistencia sanitaria.

ii. Recabarán posteriormente el parte de baja, cuando pueda ser expedido por el facultativo de la entidad o servicio público de salud.

iii. Comunicarán a MUFACE, mediante la aplicación informática habitual, la emisión de las licencias con referencia a los periodos temporales a los que correspondan.

b. Para los mutualistas de MUFACE que alcancen el día $91 .^{\circ}$ de la situación de incapacidad temporal durante la vigencia del estado de alarma, y para los mutualistas de MUGEJU en la misma situación a partir del día $181 .^{\circ}$ de la situación de incapacidad temporal, los órganos de personal:

i. Continuarán emitiendo licencias por enfermedad, aun cuando no dispongan del parte de baja acreditativo del proceso patológico y la asistencia sanitaria.

ii. Recabarán posteriormente el parte de baja cuando pueda ser expedido por el facultativo de la entidad o servicio público de salud.

iii. Comunicarán a MUFACE y a MUGEJU por el procedimiento habitual, a través de la aplicación informática habitual, los periodos temporales a los que corresponden las licencias

iv. Seguirán abonando el 100\% de las retribuciones, sin efectuar el descuento de las retribuciones complementarias hasta que no finalice el estado de alarma.

v. MUFACE y MUGEJU compensarán las cantidades equivalentes al subsidio de incapacidad temporal a la entidad que haya continuado abonando estas retribuciones con posterioridad y previa acreditación del cumplimiento de los requisitos. Ésta se realizará mediante el ingreso de dichas cantidades en el Tesoro o en la caja de la entidad pagadora.

2. Si la situación de incapacidad temporal se iniciase durante el estado de alarma, los órganos de personal:

a. Podrán emitir la licencia inicial y, en su caso, las prórrogas de la misma aun cuando no dispongan del parte de baja acreditativo del proceso patológico y la asistencia sanitaria. 
b. Recabarán posteriormente el parte de baja cuando pueda ser expedido por el facultativo de la entidad o servicio público de salud.

c. Comunicarán la situación de incapacidad temporal a MUFACE y MUGEJU mediante la aplicación informática habitual en el caso de MUFACE y el procedimiento utilizado de manera habitual con MUGEJU.

\subsection{Medidas de apoyo a las empresas y autónomos}

En relación a los autónomos se prevén medidas dirigidas, por un lado, a atender las situaciones de cese de actividad (3.2.1); como para flexibilizar el cumplimiento de la obligaciones de cotización y pago de deudas y exoneración de cuotas en caso de ERTE por fuerza mayor (3.2.3 a 3.2.4)37. Medidas estas últimas también extensibles a las empresas.

3.2.1. Prestación extraordinaria por cese de actividad de autónomos y socios cooperativistas encuadrados como trabajadores por cuenta propia

La DF $2^{a}$ del RDLey 13/20 da una nueva redacción al artículo 17 del RDLey 8/20 que regula la prestación por cese de actividad de trabajadores autónomos y cooperativistas (que, recuérdese, había sido también modificada por la DF 1ª del RDLey 11/20).

El nuevo régimen queda como sigue:

- Beneficiarios / Hecho causante: Con carácter excepcional y vigencia limitada hasta el último día del mes en que finalice el estado de alarma ex RD 463/20, tienen tendrán derecho a una prestación extraordinaria por cese de actividad:

a. Los trabajadores autónomos incluidos en el RETA, los trabajadores autónomos agrarios incluidos en el Sistema Especial para Trabajadores por Cuenta Propia Agrarios y los trabajadores autónomos incluidos en el Régimen Especial de Trabajadores del Mar cuyas actividades queden suspendidas, en virtud de lo previsto en el RD 463/20.

b. Los trabajadores autónomos incluidos en el RETA, los trabajadores autónomos agrarios incluidos en el Sistema Especial para Trabajadores por Cuenta Propia

37 Por otra parte, debe tenerse en cuenta que el RDLey 11/20 regula en su artículo 28 el derecho a percepción del bono social por parte de trabajadores autónomos que hayan cesado su actividad o hayan visto reducida su facturación como consecuencia del COVID-19. Medida que ha sido desarrollada por la Orden TED/320/2020, de 3 de abril. 
Agrarios y los trabajadores autónomos incluidos en el Régimen Especial de Trabajadores del Mar que, no cesando en su actividad, su facturación en el mes natural anterior al que se solicita la prestación se vea reducida, al menos, en un $75 \%$ en relación con el promedio de facturación del semestre natural anterior, siempre que no se encuentren en algunos de los supuestos recogidos en las letras c) y d) siguientes.

c. Los trabajadores autónomos agrarios de producciones de carácter estacional incluidos en el Sistema Especial para Trabajadores por Cuenta Propia Agrario, así como los trabajadores de producciones pesqueras, marisqueras o de productos específicos de carácter estacional incluidos en el Régimen Especial de Trabajadores del Mar, cuando su facturación promedio en los meses de campaña de producción anteriores al que se solicita la prestación se vea reducida, al menos, en un $75 \%$ en relación con los mismos meses de la campaña del año anterior.

d. Los trabajadores autónomos que desarrollen actividades en alguno de los siguientes códigos de la CNAE 2009: 5912, 5915, 5916, 5920 y entre el 9001 y el 9004 ambos incluidos, siempre que, no cesando en su actividad, su facturación en el mes natural anterior al que se solicita la prestación se vea reducida en al menos un 75 por ciento en relación con la efectuada en los 12 meses anteriores.

Debe tenerse en cuenta que la acreditación de la reducción de la facturación se realizará mediante la aportación de la información contable que lo justifique, pudiendo hacerse a través de la copia del libro de registro de facturas emitidas y recibidas; del libro diario de ingresos y gastos; del libro registro de ventas e ingresos; o del libro de compras y gastos. Aquellos trabajadores autónomos que no estén obligados a llevar los libros que acreditan el volumen de actividad, deberán acreditar la reducción al menos del 75\% exigida por cualquier medio de prueba admitido en derecho. Toda solicitud deberá ir acompañada de una declaración jurada en la que se haga constar que se cumplen todos los requisitos exigidos para causar derecho a esta prestación.

Por otra parte, los socios trabajadores de las cooperativas de trabajo asociado que hayan optado por su encuadramiento como trabajadores por cuenta propia en el régimen especial que corresponda tendrán derecho igualmente a esta prestación extraordinaria, siempre que reúnan los requisitos establecidos en el este artículo. 
- Requisitos para causar derecho a esta prestación:

a. Estar afiliados y en alta, en la fecha de la declaración del estado de alarma, en el Régimen Especial de la Seguridad Social de los Trabajadores por Cuenta Propia o Autónomos o, en su caso, en el Régimen Especial de la Seguridad Social de los Trabajadores del Mar.

b. En el supuesto de que su actividad no se vea directamente suspendida ex RD 463/20, acreditar la reducción de sus ingresos en, al menos, un $75 \%$, en los periodos recogidos en las anteriores letras b), c) y d).

c. Hallarse al corriente en el pago de las cuotas a la Seguridad Social. No obstante, si en la fecha de la suspensión de la actividad o de la reducción de la facturación, como consecuencia de la declaración del estado de alarma, no se cumpliera este requisito, el órgano gestor invitará al pago al trabajador autónomo para que en el plazo improrrogable de treinta días naturales ingrese las cuotas debidas. La regularización del descubierto producirá plenos efectos para la adquisición del derecho a la protección.

d. No será necesario para causar derecho a esta prestación tramitar la baja en el régimen de Seguridad Social correspondiente.

- Cuantía: La cuantía de la prestación regulada en este artículo se determinará aplicando el $70 \%$ a la base reguladora, calculada de conformidad con lo previsto en el artículo 339 LGSS.

Cuando no se acredite el período mínimo de cotización para tener derecho a la prestación, la cuantía de la prestación será equivalente al $70 \%$ de la base mínima de cotización en el Régimen Especial de la Seguridad Social de los Trabajadores por Cuenta Propia o Autónomos o, en su caso, en el Régimen Especial de la Seguridad Social de los Trabajadores del Mar, que les corresponda por actividad.

- Duración: Duración de un mes, ampliándose, en su caso, hasta el último día del mes en el que finalice el estado de alarma, en el supuesto de que este se prorrogue y tenga una duración superior al mes. El tiempo de su percepción se entenderá como cotizado, no existirá obligación de cotizar y no reducirá los períodos de prestación por cese de actividad a los que el beneficiario pueda tener derecho en el futuro.

- Compatibilidad: Esta prestación será compatible con cualquier otra prestación de seguridad social que el beneficiario viniera percibiendo y fuera compatible con el 
desempeño de la actividad que desarrollaba. Por lo que se refiere a los trabajadores por cuenta propia incluidos en el Régimen Especial de los Trabajadores del Mar, la prestación por cese de actividad será incompatible con la percepción de la ayudas por paralización de la flota.

- Suspensión, cotización y recargo: En el supuesto de suspensión de la actividad, la cotización correspondiente a los días de actividad en el mes de marzo de 2020 no cubiertos por la prestación regulada en este artículo, que no fuera abonada dentro del plazo reglamentario de ingreso, no será objeto del recargo previsto en el artículo 30 LGSS.

- Solicitud y revisión: El reconocimiento de la prestación regulada en este artículo podrá solicitarse hasta el último día del mes siguiente al que se produjo la finalización del estado de alarma. Las entidades gestoras, de acuerdo con la solicitud presentada y los documentos en su caso aportados, dictará la resolución provisional que sea procedente, estimando o desestimando el derecho.

Finalizado el estado de alarma se procederá a revisar todas las resoluciones provisionales adoptadas. En el supuesto de que se desprenda que el interesado no tiene derecho a la prestación, se iniciarán los trámites de reclamación de las cantidades indebidamente percibidas 38 .

\subsubsection{Moratoria de las cotizaciones sociales a la Seguridad Social}

- Beneficiarios y afectación: En virtud del artículo 34 RDLey 11/20 (redactado conforme a la DF $3^{\text {a }}$ RDLey 13/20), se habilita a la Tesorería General de la Seguridad Social a otorgar moratorias de seis meses, sin interés, a las empresas y los trabajadores por cuenta propia incluidos en cualquier régimen de la Seguridad Social, que lo soliciten y cumplan los requisitos y condiciones que se establecerán mediante Orden del Ministro de Inclusión, Seguridad Social y Migraciones, previo acuerdo de la Comisión Delegada del Gobierno para Asuntos Económicos.

La moratoria, en los casos que sea concedida, afectará al pago de las aportaciones empresariales a la cotización a la Seguridad Social y por conceptos de recaudación conjunta y a las cuotas de los trabajadores por cuenta propia o autónomos, cuyo período de devengo, en el caso de las empresas esté comprendido entre los meses de abril y junio de 2020 y, en el caso de los trabajadores por cuenta propia entre mayo

38 Finalmente, puede acceder a las Instrucciones provisionales del SEPE para la aplicación de estas reglas aquí (aunque debe advertirse que son anteriores al RDLey 13/2020). 
y julio de 2020, siempre que las actividades que realicen no se encuentren suspendidas con ocasión del estado de alarma declarado por el Real Decreto 463/20.

- Solicitud: Las solicitudes, que deben tramitarse a través del sistema RED o por los medios electrónicos disponibles en la sede electrónica de la Secretaría de Estado de la Seguridad Social (SEDESS), deben comunicarse a la TGSS dentro de los 10 primeros días naturales de los plazos reglamentarios de ingreso correspondientes a los períodos de devengo anteriormente indicados (en ningún caso procederá la moratoria de aquellas cotizaciones cuyo plazo reglamentario de ingreso haya finalizado con anterioridad a dicha solicitud).

- Comunicación: La concesión de la moratoria se comunicará en el plazo de los tres meses siguientes al de la solicitud. No obstante, se considerará realizada dicha comunicación con la efectiva aplicación de la moratoria por parte de la Tesorería General de la Seguridad Social en las liquidaciones de cuotas que se practiquen a partir del momento en que se presente la solicitud.

- Exclusión de la moratoria: La moratoria no será de aplicación a los códigos de cuenta de cotización por los que las empresas hayan obtenido exenciones en el pago de la aportación empresarial así como en las cuotas de recaudación conjunta, ex artículo 24 RDLey 8/20, como consecuencia de los procedimientos de suspensión de contratos y reducción de jornada por fuerza mayor.

- Régimen sancionador: En virtud de la LISOS, las solicitudes presentadas por las empresas, o por los trabajadores por cuenta propia, que contuvieran falsedades o incorrecciones en los datos facilitados darán lugar a las sanciones correspondientes. Se entiende por tal, comunicar a la TGSS en la solicitud de inscripción como empresa, o en el alta del trabajador en el correspondiente Régimen Especial, o en variación de datos posterior a la inscripción, o al alta, una actividad económica falsa o incorrecta, así como aquellos otros datos que determinen la existencia de las condiciones y requisitos a los que se refiere el apartado primero.

El reconocimiento indebido de moratorias como consecuencia de alguno de los incumplimientos anteriormente descritos, dará lugar a la revisión de oficio del acto de reconocimiento de la moratoria. En estos casos, y sin perjuicio de la responsabilidad administrativa o penal que legalmente corresponda, la empresa, o el trabajador por cuenta propia, resultarán de aplicación a las cuotas a las que se hubiese aplicado indebidamente la moratoria el correspondiente recargo e intereses ex Reglamento General de Recaudación de la Seguridad Social. 


\subsubsection{Aplazamiento en el pago de deudas con la Seguridad Social}

Las empresas y los trabajadores por cuenta propia incluidos en cualquier régimen de la Seguridad social o los autorizados para actuar a través del Sistema de remisión electrónica de datos en el ámbito de la Seguridad Social (Sistema RED), siempre que no tuvieran otro aplazamiento en vigor, podrán de acuerdo con el artículo 35 RDLey 11/20 solicitar hasta el 30 de junio de 2020 el aplazamiento en el pago de sus deudas con la Seguridad Social cuyo plazo reglamentario de ingreso tenga lugar entre los meses de abril y junio de 2020, en los términos y condiciones establecidos en la normativa de Seguridad Social, siendo de aplicación un interés del 0,5\% en lugar del previsto en el artículo 23.5 LGSS.

Estas solicitudes de aplazamiento deberán efectuarse antes del transcurso de los diez primeros naturales del plazo reglamentario de ingreso.

\subsubsection{ERTE por fuerza mayor y exoneración de la cuota empresarial}

En los expedientes de suspensión de contratos y reducción de jornada autorizados en base a fuerza mayor ex artículo 22 RDLey 8/20, también se prevén algunas medidas de exoneratorias de las cuotas empresariales 39.

En concreto, el artículo 24 RDLey 8/20 prevé la exoneración del abono de la aportación empresarial prevista en el artículo 273.2 LGSS así como del relativo a las cuotas por conceptos de recaudación conjunta si la empresa tiene menos 50 trabajadores en situación de alta en la Seguridad Social. Si la empresa tuviera 50 trabajadores o más, en situación de alta en la Seguridad Social, la exoneración de la obligación de cotizar alcanzará al 75\% de la aportación empresarial.

Para los trabajadores este período tiene la consideración como efectivamente cotizado a todos los efectos.

La exoneración de cuotas se aplicará por la Tesorería General de la Seguridad Social a instancia del empresario, previa comunicación de la identificación de los trabajadores y período de la suspensión o reducción de jornada. A efectos del control de la exoneración de cuotas será suficiente la verificación de que el Servicio Público de Empleo Estatal

39 Estas medidas, según la DT $1^{\text {a }}$ RDLey 8/20 (redactada según la DF $1^{\text {a }}$ RDLey 9/20), “serán de aplicación a los afectados por los procedimientos de suspensión de contratos y reducción de jornada comunicados, autorizados o iniciados, con anterioridad a la entrada en vigor de este real decreto ley, siempre que deriven directamente del COVID-19”. 
proceda al reconocimiento de la correspondiente prestación por desempleo por el período de que se trate.

\subsection{Medidas dirigidas a trabajadores por cuenta ajena y autónomos: disponibilidad de los planes de pensiones}

En los casos de desempleo y cese de actividad, se ha previsto la posibilidad de dispone de los planes de pensiones con las siguientes particularidades.

\section{- Supuestos que habilitan la disponibilidad}

La DA $20^{\text {a }}$ RDLey $11 / 20$ prevé que durante el plazo de seis meses (que puede ser ampliable) desde la entrada en vigor del RD 463/20, los partícipes de los planes de pensiones (y de planes de previsión asegurados, planes de previsión social empresarial y mutualidades de previsión social) podrán, excepcionalmente, hacer efectivos sus derechos consolidados en los siguientes supuestos:

a. Encontrarse en situación legal de desempleo como consecuencia de un ERTE derivado de la situación de crisis sanitaria ocasionada por el COVID-19.

b. Ser empresario titular de establecimientos cuya apertura al público se haya visto suspendida como consecuencia de lo establecido en el artículo 10 RD 463/20.

c. En el caso de los trabajadores por cuenta propia que hubieran estado previamente integrados en un régimen de la Seguridad Social como tales y hayan cesado en su actividad como consecuencia de la situación de crisis sanitaria ocasionada por el COVID-19.

El plazo de 6 meses podrá ampliarse teniendo en cuenta las necesidades de renta disponible ante la situación derivada de las circunstancias de la actividad económica provocadas como consecuencia de la situación de crisis sanitaria ocasionada por el COVID-19.

- Importe de los derechos consolidados disponible

El importe de los derechos consolidados disponible, previa acreditación del solicitante, no podrá ser superior a:

a. Los salarios dejados de percibir mientras se mantenga la vigencia del ERTE para el supuesto previsto en el apartado 1.a). 
b. Los ingresos netos estimados que se hayan dejado de percibir mientras se mantenga la suspensión de apertura al público para el supuesto recogido en el apartado 1.b).

c. Los ingresos netos estimados que se hayan dejado de percibir mientras se mantenga la situación de crisis sanitaria ocasionada por el COVID-19 para el supuesto recogido en el apartado 1.c).

- Solicitud

Sin perjuicio del desarrollo reglamentario que pueda establecerse, el reembolso de derechos consolidados se hará efectivo a solicitud del partícipe, sujetándose al régimen fiscal establecido para las prestaciones de los planes de pensiones. El reembolso deberá efectuarse dentro del plazo máximo de siete días hábiles desde que el partícipe presente la documentación acreditativa correspondiente.

\section{Ampliación plazo para recurrir y agilización procesal}

La DA $8^{\text {a }}$ RDLey $11 / 20$ amplia el plazo para recurrir, estableciendo que

"El cómputo del plazo para interponer recursos en vía administrativa o para instar cualesquiera otros procedimientos de impugnación, reclamación, conciliación, mediación y arbitraje que los sustituyan de acuerdo con lo previsto en las Leyes, en cualquier procedimiento del que puedan derivarse efectos desfavorables o de gravamen para el interesado, se computará desde el día hábil siguiente a la fecha de finalización de la declaración del estado de alarma, con independencia del tiempo que hubiera transcurrido desde la notificación de la actuación administrativa objeto de recurso o impugnación con anterioridad a la declaración del estado de alarma. Lo anterior se entiende sin perjuicio de la eficacia y ejecutividad del acto administrativo objeto de recurso o impugnación".

Y la DA $19^{a}$ RDLey $11 / 20$ prevé que, una vez que se haya dejado sin efecto la declaración del estado de alarma y de sus prórrogas, a propuesta del Ministerio de Justicia, se aprobará a la mayor brevedad posible y en todo caso en el plazo máximo de 15 días, un Plan de Actuación para agilizar la actividad judicial en los órdenes jurisdiccionales social y contencioso-administrativo así como en el ámbito de los Juzgados de lo mercantil con la finalidad de contribuir al objetivo de una rápida recuperación económica tras la superación de la crisis. 


\section{Valoración final}

La situación que estamos viviendo era, hace unas semanas, inimaginable y está evidenciado la extrema fragilidad de nuestro modo de vida.

Al sentimiento de incredulidad generalizado, se le une el temor y la ansiedad derivada de la incertidumbre sobre el devenir político, social y económico (al menos, a corto y medio plazo). Y el hecho de vivir en la "sociedad del miedo", en la que (BUDE, 2017: 79) nuestra «sensibilidad para las inseguridades crece en la misma medida en que lo hace la seguridad», probablemente, no contribuya al sosiego que una situación de esta naturaleza exigiría.

De hecho, damos por sentado que la alarma sanitaria es pasajera y, víctimas - quizás de un exceso de optimismo, no podemos evitar "asomarnos a un futuro" en lo que todo vuelve a la "normalidad". No obstante, el confinamiento también nos ha atrapado en el presente más inmediato y, a pesar de que hoy parece lo más probable (al menos a corto plazo), tenemos muchos problemas para proyectarnos a escenarios mediatos en los que la convivencia con el COVID-19 forme parte de nuestra cotidianiedad.

Creo que deberíamos interiorizar la factibilidad de esta posibilidad cuanto antes.

Aunque deseemos despertarnos de esta pesadilla (y "pasar página" cuanto antes), no sabemos qué nos deparará el futuro más inmediato; y, por consiguiente, tampoco podemos saber cómo será el contexto político, social y económico ni tampoco las relaciones laborales que en él se desarrollarán. Ni por supuesto si alguna de las medidas legislativas de emergencia que se han adoptado (o las que eventualmente puedan dictarse en un futuro inmediato) permanecerán en el tiempo y, marcando un punto de inflexión, son el preludio de un cambio sistémico.

No saben cuánto deseo errar en mi predicción.

\section{Bibliografía citada}

AnEXPAL (2020), «Permiso recuperable: de aplicación a las administraciones locales? Nota interpretativa de la Comisión de Coordinación del Empleo Público», Blog Anexpal, https://anexpal.com/2020/03/30/permiso-recuperable-de-aplicacion-a-lasadministraciones-locales-nota-interpretativa-de-la-comision-de-coordinacion-delempleo-publico/ 
ARAGÓN GÓMEZ, C. (2020), Claves prácticas del permiso retribuido recuperable», Foro de Labos, https://forodelabos.blogspot.com/2020/04/claves-practicas-del-permisoretribuido.html

Arenas GómEz, M. (2020), «Aspectos en materia de seguridad social del rdley 10/2020, sobre permisos retribuidos recuperables», Blog del Autor, https://miguelonarenas.blogspot.com/2020/03/aspectos-en-materia-de-seguridadsocial.html

ARriETA IRIAKEZ, F. J. (2020), «Consecuencias del Covid-19 en el régimen profesional de las cooperativas», Foro de Labos, https://forodelabos.blogspot.com/2020/04/consecuencias-del-covid-19-en-el.html

FERIA BASILIO, I. (2020), «La prevención de riesgos laborales en tiempo de coronavirus», Blog Trabajo, Persona, Derecho y Mercado, http://grupo.us.es/iwpr/covid-19-y-derecho-social/la-prevencion-de-riesgos-laboralesen-tiempo-de-coronavirus/

BAYlos GRAU, A. (2020). «La prórroga del estado de alarma y medidas laborales adicionales de garantía del empleo en la crisis del covid-19». Blog del Autor, https://baylos.blogspot.com/2020/03/la-prorroga-del-estado-de-alarma-y.html

Beltran De Heredia RuIZ, I. (2020, 1). «COVID-19 y ERTE por fuerza mayor: situaciones que lo justifican y acreditación». Blog del Autor, https://ignasibeltran.com/2020/03/27/covid-19-y-erte-por-fuerza-mayor-situacionesque-lo-justifican-y-acreditacion/

Beltran De Heredia Ruiz, I. (2020, 2). «La constatación de la fuerza mayor por la autoridad laboral». Blog del Autor, https://ignasibeltran.com/2020/03/18/laconstatacion-de-la-fuerza-mayor-por-la-autoridad-laboral/

BELTRAN DE HEREDIA RUIZ, I (2020, 3). «ERTE por imposibilidad objetiva temporal: algunos ejemplos jurisprudenciales». Blog del Autor, https://ignasibeltran.com/2020/03/22/erte-por-imposibilidad-objetiva-temporal-algunosejemplos-jurisprudenciales/

Beltran De Heredia Ruiz, I. (2019). «Engaño y deshonestidad (¿tenemos una falsa percepción de rectitud moral?)». Blog del Autor, https://ignasibeltran.com/2019/12/09/engano-y-deshonestidad-tenemos-una-falsapercepcion-de-rectitud-moral/ 
BudE, H. (2017). La sociedad del miedo. Herder.

Calvo Gallego, J. (2020, 1), «Presentación de los comentarios a las medidas sociolaborales ligadas a la crisis sanitaria», Blog Trabajo, Persona, Derecho y Mercado, http://grupo.us.es/iwpr/2020/04/02/presentacion-de-los-comentarios-a-las-medidassociolaborales-ligadas-a-la-crisis-sanitaria/

Calvo Gallego, J. (2020, 3), «Trabajo a distancia y otras medidas alternativas», Blog Trabajo, Persona, Derecho y Mercado, http://grupo.us.es/iwpr/covid-19-y-derechosocial/objetivos-y-principales-medidas-en-el-plano-laboral/trabajo-a-distancia/

Calvo Gallego, J. (2020, 3), «Incapacidad temporal y COVID-19», Blog Trabajo, Persona, Derecho y Mercado, http://grupo.us.es/iwpr/covid-19-y-derechosocial/aspectos-de-seguridad-social/incapacidad-temporal-y-covid-19/

Calvo Gallego, J (2020, 4), «COVID-19 y extinción del contrato: mucho ruido para qué nueces...», Blog Trabajo, Persona, Derecho y Mercado, http://grupo.us.es/iwpr/covid-19-y-derecho-social/objetivos-y-principales-medidas-enel-plano-laboral/covid-19-y-extincion-del-contrato-mucho-ruido-para-que-nueces/

Calvo Gallego, J (2020, 5), «Interrupción del cómputo de la duración máxima de los contratos temporales», Blog Trabajo, Persona, Derecho y Mercado, http://grupo.us.es/iwpr/2020/03/31/interrupcion-del-computo-de-la-duracion-maximade-los-contratos-temporales/

Calvo Gallego, y Rodríguez-Piñero Royo, M. C. (2020), «El tratamiento de los ERTE durante la actual crisis sanitaria»Blog Trabajo, Persona, Derecho y Mercado, http://grupo.us.es/iwpr/2020/04/02/el-tratamiento-de-los-erte-durante-la-actual-crisissanitarial

De La VILla GIL, L. (1970). «El 'factum principis'». En Diecisiete lecciones sobre fuerza mayor, crisis de trabajo, reconversión y empleo. Universidad de Madrid Facultad de Derecho

FERNÁNDEZ AviLÉS, J. A. (2020), «¿Es suficiente este derecho laboral excepcional «por aluviones» frente a la pandemia del COVID-19?», CEF-RTSS, núm. 445.

FERNÁNDEZ DOMÍNGUEZ (1993). La fuerza mayor como causa de extinción y suspensión del contrato de trabajo. Civitas. Madrid 
GoRdo GonZÁleZ, L. (2020). «RDL 10/2020: ¿se aplica el permiso retribuido recuperable obligatorio a los empleados públicos?» Instituto de Derecho Local - UAM, https://www.idluam.org/blog/rdl-10-2020-se-aplica-el-permiso-retribuido-recuperableobligatorio-previsto-a-los-empleados-publicos/

JiMÉNEZ ASENSIO, R. (2020). «Un apunte sobre el permiso retribuido recuperable y los empleados públicos». Blog del Autor https://rafaeljimenezasensio.com/documentos/

Martínez Aso, M. (2020), «Una pequeña consideración de mi ámbito (lógico, el sancionador) sobre el permiso retribuido y el RDL 10/2020». Blog de Eduardo Rojo, http://www.eduardorojotorrecilla.es/2020/03/una-pequena-consideracion-de-miambito.html

MerCAder Uguina, J. R. (2020, 1), «El silencio administrativo positivo y ERTES por fuerza mayor: la negra sombra del Barón de Rothschild», Foro de Labos, https://forodelabos.blogspot.com/2020/04/el-silencio-administrativo-positivo-y.html

Mercader Uguina, J. R. (2020, 2), «Compromiso de empleo en los ERTES por fuerza mayor y COVID-19: más dudas, más incertidumbre», Foro de Labos, https://forodelabos.blogspot.com/2020/03/compromiso-de-empleo-en-los-ertes-por.html

Morales OrtegA, J. M. (2020), «La adaptación y la reducción de la jornada como medidas laborales ante la crisis sanitaria» Blog Trabajo, Persona, Derecho y Mercado, http://grupo.us.es/iwpr/covid-19-y-derecho-social/objetivos-y-principales-medidas-enel-plano-laboral/adaptacion-y-reduccion-de-jornada/

Moreno SolanA, A. (2020), «Prevención de Riesgos Laborales y Covid-19 (coronavirus): dificultades para el cumplimiento de las obligaciones preventivas», Foro de Labos, https://forodelabos.blogspot.com/2020/03/prevencion-de-riesgos-laborales-ycovid.html

NiETo RojAs, P. (2020), «COVID-19 y ERTES por causas económicas: ¿con quién negocia la empresa? nuevamente más incertidumbres que certezas», Foro de Labos, https://forodelabos.blogspot.com/2020/03/covid-19-y-ertes-por-causas-economicas.html

ORTIZA LALlana, M. C. (1985). La extinción del contrato de trabajo por imposibilidad física de cumplimiento. MTSS. Madrid

Pedrajas Moreno, A. (1983). La excedencia en el derecho español. Editorial de la Universidad de Complutense de Madrid, 1983 
RAmírez MARTíneZ, J. M. (1994). «Naturaleza y fines de la suspensión del contrato: delimitación frente a figuras afines». En La suspensión del contrato (Dir. Marín Correa). CDJ XXX.

RiVERo LAMAS, J. (1972), «Tipificación y estructura del contrato de trabajo». ADC

Rojo Torrecilla, E. (2020), «Emergencia sanitaria y legislación laboral. Primeras notas sobre el Real Decreto-ley 9/2020, de 27 de marzo, por el que se adoptan medidas complementarias, en el ámbito laboral, para paliar los efectos derivados del COVID19», Blog del Autor, http://www.eduardorojotorrecilla.es/2020/03/emergencia-sanitariay-legislacion.html

TALÉns VisConTI, E. E. (2020), «Análisis de las medidas de Seguridad Social adoptadas por el Gobierno de España en relación con la crisis del COVID-19». CEF-RTSS, núm. 445.

TorralbA, F. (2020), «Segunda parte.- Permiso retribuido recuperable en las Administraciones Públicas», La organización y gestión de las personas https://finitorralba.blogspot.com/2020/04/segunda-parte-permisoretribuido.html?spref $=\mathrm{tw}$

VIDA SORIA, J. (1966). «La configuración jurídica general de la suspensión del contrato de trabajo». RPS n 70.

Última consulta de todos los enlaces: 09/04/2020. 